\title{
Distribution, source, water quality and health risk assessment of dissolved heavy metals in major rivers in Wuhan, China
}

\author{
Xingyong Zhang ${ }^{1}$, Qixin Wu ${ }^{\text {Corresp., } 1,2}{ }^{2}$, Shilin Gao ${ }^{1}$, Zhuhong Wang ${ }^{3}$, Shouyang He ${ }^{1}$ \\ ${ }^{1}$ Guizhou University, Key Laboratory of Karst Geological Resources and Environment, Ministry of Education, Guiyang, Guizhou, China \\ 2 Guizhou University, The College of Resources and Environmental Engineering, Guiyang, Guizhou, China \\ 3 Guizhou Medical University, School of Public Health, Key Laboratory of Environmental Pollution and Disease Monitoring of Ministry of Education, Guiyang, \\ Guizhou, China \\ Corresponding Author: Qixin Wu \\ Email address: qxwu@gzu.edu.cn
}

Heavy metals are released into the water system through various natural processes and anthropogenic activities, thus indirectly or directly endangering human health. The distribution, source, water quality and health risk assessment of dissolved heavy metals $(\mathrm{V}, \mathrm{Mn}, \mathrm{Fe}, \mathrm{Co}, \mathrm{Ni}, \mathrm{Zn}, \mathrm{As}, \mathrm{Mo}, \mathrm{Sb})$ in major rivers in Wuhan were analyzed by correlation analysis (CA), principal component analysis (PCA), heavy metal pollution index (HPI), hazard index $(\mathrm{HI})$ and carcinogenic risk $(\mathrm{CR})$. The results showed that the spatial variability of heavy metal contents was pronounced. PCA and CA results indicated that natural sources controlled $\mathrm{Mn}, \mathrm{Fe}, \mathrm{Co}, \mathrm{Ni}$ and $\mathrm{Mo}$, and industrial emissions were the dominant factor for $\mathrm{V}, \mathrm{Zn}$ and $\mathrm{Sb}$, while As was mainly from the mixed input of urban and agricultural activities. According to the heavy metal pollution index (HPI, ranging from 23.74 to 184.0) analysis, it should be noted that As and Sb contribute most of the HPI values. The health risk assessment using $\mathrm{HI}$ and $\mathrm{CR}$ showed that $\mathrm{V}$ and $\mathrm{Sb}$ might have a potential noncarcinogenic risk and As might have a potential carcinogenic risk to adults and children in the study area (CR value exceeded target risk $\left.10^{-4}\right)$. At the same time, it was worth noting that As might have a potential non-carcinogenic risk for children around QLR (HI value exceeded the threshold value 1). The secular variation of As and Sb should be monitor in high-risk areas. The results of this study can provide important data for improving water resources management efficiency and heavy metal pollution prevention in Wuhan. 


\section{Distribution, source, water quality and health risk}

\section{2 assessment of dissolved heavy metals in major rivers in}

\section{Wuhan, China}

Xingyong Zhang ${ }^{1}$, Qixin $\mathrm{Wu}^{1,2}$, Shilin $\mathrm{Gao}^{1}$, Zhuhong Wang ${ }^{3}$, Shouyang $\mathrm{He}^{1}$ 7

$8{ }^{1}$ Key Laboratory of Karst Geological Resources and Environment, Ministry of Education,

9 Guizhou University, Guiyang, China

$10{ }^{2}$ The College of Resources and Environmental Engineering, Guizhou University, Guiyang,

11 China

$12{ }^{3}$ School of Public Health, Key Laboratory of Environmental Pollution and Disease Monitoring

13 of Ministry of Education, Guizhou Medical University, Guiyang, China

Corresponding Author:

16 Qixin $\mathrm{Wu}^{1,2}$

17 Guiyang, Guizhou Province, 550000, China

18 Email address: qxwu@gzu.edu.cn

\section{Abstract}

Heavy metals are released into the water system through various natural processes and anthropogenic activities, thus indirectly or directly endangering human health. The distribution, source, water quality and health risk assessment of dissolved heavy metals (V, Mn, Fe, Co, Ni, $\mathrm{Zn}, \mathrm{As}, \mathrm{Mo}, \mathrm{Sb}$ ) in major rivers in Wuhan were analyzed by correlation analysis (CA), principal component analysis (PCA), heavy metal pollution index (HPI), hazard index (HI) and carcinogenic risk (CR). The results showed that the spatial variability of heavy metal contents was pronounced. PCA and CA results indicated that natural sources controlled $\mathrm{Mn}, \mathrm{Fe}, \mathrm{Co}, \mathrm{Ni}$ and $\mathrm{Mo}$, and industrial emissions were the dominant factor for $\mathrm{V}, \mathrm{Zn}$ and $\mathrm{Sb}$, while As was mainly from the mixed input of urban and agricultural activities. According to the heavy metal pollution index (HPI, ranging from 23.74 to 184.0) analysis, it should be noted that As and $\mathrm{Sb}$ contribute most of the HPI values. The health risk assessment using HI and CR showed that $\mathrm{V}$ 
33 and $\mathrm{Sb}$ might have a potential non-carcinogenic risk and As might have a potential carcinogenic 34 risk to adults and children in the study area (CR value exceeded target risk $10^{-4}$ ). At the same 35 time, it was worth noting that As might have a potential non-carcinogenic risk for children 36 around QLR (HI value exceeded the threshold value 1). The secular variation of As and $\mathrm{Sb}$ 37 should be monitor in high-risk areas. The results of this study can provide important data for 38 improving water resources management efficiency and heavy metal pollution prevention in 39 Wuhan.

\section{Introduction}

42 With the rapid development of the social economy, industry, agriculture, medicine, and mining 43 activities are increasing, which have seriously affected the quality of surface water worldwide 44 (Gao et al. 2020; Wang et al. 2017; Zeng et al. 2020). Heavy metals have the characteristics of toxicity, persistence and bioaccumulation, which cause environmental pollution to the water ecosystem and threaten human health (Cameron et al. 2018; Zaric et al. 2018; Zeng et al. 2019). There are two main exposure pathways (direct ingestion and dermal absorption) of heavy metals in water bodies (Gao et al. 2020; Giri \& Singh 2014). However, aquatic foods and plants as human food sources may also lead to the exposure of heavy metals in water (Krishnamurti et al. 2015; Qu et al. 2018). Therefore, due to the bioaccumulation of heavy metals, even if humans do not directly drink or contact water contaminated by heavy metals, they will also be exposed to high levels of heavy metals from food (Antoniadis et al. 2016; Jiang et al. 2016). Thus, the pollution of heavy metals in the water environment has been widely concerned worldwide (Ali et al. 2016; Chowdhury et al. 2016; Zeng \& Han 2020a; Zeng \& Han 2020b).

Heavy metals enter the water body mainly through natural processes (atmospheric dry/wet deposition, rock weathering and volcanism) and anthropogenic activities (industrial, agricultural, medical and urban sewage) (Han \& Liu 2004; Han et al. 2019; Krishna et al. 2009; Li \& Zhang 2010; Meng et al. 2016). The metal availability of organisms is determined by the concentration and species of heavy metals in water. Therefore, more attention should be paid to heavy metals in surface water because these heavy metals may affect human health through food, water and body contact (Qu et al. 2018). The study of the concentration, distribution, source, water quality and health risk levels of dissolved heavy metals in surface water is the basis for the effective control of water pollution and the maintenance of water ecosystem health (Xiao et al. 2014; Xiao et al. 2019). 
67 Correlation analysis (CA) and principal component analysis (PCA) are common tools for

68 studying heavy metals in water environment. They can better identify the natural or

69 anthropogenic sources of heavy metals (Gao et al. 2020; Giri \& Singh 2014; Qu et al. 2018;

70 Thuong et al. 2013; Wang et al. 2017; Xiao et al. 2019). Furthermore, heavy metal pollution

71 index (HPI) was used to analyze the combined effects on water quality (Tiwari et al. 2015).

72 Hazard quotient (HQ), hazard index (HI) and carcinogenic risk (CR) are commonly used to

73 assess human health risks of heavy metals (Qu et al. 2018; Wang et al. 2017; Wu et al. 2009b;

74 Zeng et al. 2019). Moreover, geographical information system (GIS) is also used to show the

75 spatial distribution of pollutants (Qu et al. 2018; Tiwari et al. 2015).

With the growth of population and the rapid development of agriculture, cities and industries in the past decades, rivers in Wuhan have been polluted by toxic heavy metals (Gong et al. 2018; $\mathrm{Xu}$ et al. 2020a). Therefore, the sources and health risks associated with heavy metals in these rivers need to be explored to protect water resources and improve water quality. Heavy metal pollution in surface water and sediment in Wuhan has been studied a lot (Du et al. 2014; Hu et al. 2012; Yang et al. 2016). However, the systematic study on geochemical characteristics, sources, water quality and health risks of dissolved heavy metals in surface rivers of Wuhan is still lacking, especially in the analysis of spatial distribution and potential health hazards of heavy metals in surface rivers through different exposure pathways and source identification.

In this study, water from surface rivers in Wuhan was collected systematically. Nine dissolved heavy metals in the river water were analyzed, with the following objectives: (1) to understand the spatial distribution of heavy metals in surface rivers; (2) to explore the potential sources of heavy metals; (3) to evaluate river water quality and the risk level of heavy metals to human health, and to map their spatial distribution. The results can provide important information for water resources management and prevention and control of heavy metal pollution to reduce the health hazards to the public.

\section{Materials and methods}

\section{Study area}

Wuhan is located in the central part of China and the middle reaches of the Yangtze River basin 
101 the southern foot of the Dabie Mountains. The climate of Wuhan belongs to the north subtropical

102 monsoon climate, with a mean annual temperature of between $15.8^{\circ} \mathrm{C}$ and $18.5^{\circ} \mathrm{C}$. The annual

103 precipitation ranges from 1150 to $1450 \mathrm{~mm}$, of which about $40 \%$ occurs in the rainy season

104 (June to July). With a developed water system and rivers, Wuhan has formed a complex and

105 unique water area with a total water area of $2217.6 \mathrm{~km} 2$ (Xu \& Wang 2020). Eight representative

106 rivers are selected in this study, which are Yangtze River (YR), Dongjing River (DJR), Han

107 River (HR), Qingling River (QLR), Xunsi River (XSR), Fu River (FR), Sheshui River (SSR) and

108 Daoshui River (DSR) (Fig. 1). The lithology of the basin is mainly carbonate rock (Guan et al.

109 2008). Wuhan industry is developed, including automobile, chemical, steel, metallurgy, etc.

110 Heavy metal pollution in rivers is becoming more and more severe due to the long-term

111 acceptance of untreated domestic and industrial wastewater (Li 2019).

112

113 Sample collection and analysis

114 In July 2019, 34 surface water samples were collected from eight rivers in Wuhan, of which

115 YR1 9 HR1 5, DJR1 3, FR1 9, XSR1 2, QLR1 2, DSR1 2, SSR1 2 (Fig. 1), which

116 reasonably reflected the water quality of surface rivers in Wuhan. After collection, the samples

117 were immediately filtered with $0.22 \mu \mathrm{m}$ acetate fiber filter membrane and acidified with ultra-

118 pure concentrated $\mathrm{HNO}_{3}$ to $\mathrm{pH}<2$, then sealed in a pre-pickled polyethylene bottle and stored in

119 a $4{ }^{\circ} \mathrm{C}$ freezer for the determination of heavy metals. The remaining unfiltered water samples were

120 acidified with sulfuric acid to $\mathrm{pH}<2$ to determine total phosphorus and total nitrogen. The $\mathrm{pH}$,

121 electrical conductivity (EC) and dissolved oxygen (DO) were measured by portable water quality

122 analyzer (WTW Company, Weilheim, Upper Bavaria, Germany). Nine heavy metal elements (V,

$123 \mathrm{Mn}, \mathrm{Fe}, \mathrm{Co}, \mathrm{Ni}, \mathrm{Zn}, \mathrm{As}, \mathrm{Mo}$ and $\mathrm{Sb}$ ) in water samples were determined by inductively coupled

124 plasma-mass spectrometry (ICP-MS, NexION300X) of the Institute of Geochemistry, Chinese

125 Academy of Sciences. Standard reference materials (GSB04-1767-2004) were used for method

126 validation and quality control (Liu \& Han 2021; Xu et al. 2020a; Zhang et al. 2018). All samples,

127 standards and program blanks of the same batch of samples were analyzed. The recoveries

128 ranged from $90.0 \%$ to $110.4 \%$. The relative standard deviation of heavy metals is $\pm 5 \%$.

129

\section{Statistical analysis}

131 In this study, correlation analysis (CA) and principal component analysis (PCA) were used to

132 identify pollution sources. PCA is a common statistical analysis method in studying the sources

133 of heavy metal pollution (Loska \& Wiechuła 2003; Zeng et al. 2020). In the PCA analysis of the 
134 data, the feasibility of the data was tested by Kaiser-Meyer-Olkin (KMO) and Bartlett's

135 sphericity test $(\mathrm{P}<0.001)$ (Varol 2011). The principal components were extracted only when the

136 eigenvalue is greater than or equal to 1 (Kowalkowski et al. 2006). All data were processed by

137 SPSS 22.0.

138

\section{Heavy metal pollution index}

140 Heavy metal pollution index (HPI) can provide the comprehensive impact of a single heavy

141 metal on the overall water quality. The HPI model (Mohan et al. 2008; Qu et al. 2018) is given

142 by Eq. (1)

143

$$
\mathrm{H} \quad \mathrm{P}=\frac{\sum_{\mathrm{i}=1}^{\mathrm{n}}\left(\mathrm{Q}_{\mathrm{i}} \mathrm{W}_{\mathrm{i}}\right)}{\sum_{\mathrm{i}=1}^{\mathrm{n}} \mathrm{W}_{\mathrm{i}}}
$$

$144 \quad \mathrm{Q}_{\mathrm{i}}=\frac{\mathrm{c}_{\mathrm{i}}}{\mathrm{s}_{\mathrm{i}}} \times 100$

$145 \quad \mathrm{~W}_{\mathrm{i}}=\frac{\mathrm{k}}{\mathrm{s}_{\mathrm{i}}}$

147 Where $\mathrm{W}_{\mathrm{i}}$ is the unit weight of the ith parameter, which can reflect its importance. $\mathrm{Q}_{\mathrm{i}}$ is the sub148 index of the ith heavy metal parameter, and $\mathrm{n}$ is the number of parameters selected in the study. $149 \mathrm{c}_{\mathrm{i}}$ is the concentration of the ith heavy metal parameter $(\mu \mathrm{g} / \mathrm{L})$, and $\mathrm{s}_{\mathrm{i}}$ is the highest allowable 150 value of the ith parameter in drinking water standard. The value of $s_{i}$ in this study is from the 151 World Health Organization (WHO) drinking water quality guidelines (WHO 2011). Where k is 152 the proportional constant, here we take $\mathrm{K}$ as " 1 ", which is convenient for calculation (Wanda et 153 al. 2012). Now we typically use the modified scale to describe heavy metal pollution: low (HPI 154 values< 15), medium (HPI values within 15-30) and high (HPI values > 30) (Tiwari et al. 2015).

Geographic information system (GIS) is widely used to collect various spatial data to express spatial variation (Gupta \& Srivastava 2010; Qu et al. 2018; Tiwari et al. 2015). Therefore, GIS technology was used to present the results of the HPI assessment of river heavy metal ecological risk in Wuhan. The HPI values of the sampling points were inserted into the surface rivers of Wuhan by inverse distance weighted (IDW) method to show the spatial distribution. A spatial distribution map was compiled by ArcGIS 10.7 software.

162

\section{3}

\section{Human health risk assessment model}

164 Heavy metals are difficult to remove in water, and they can be recycled and bioaccumulated

165 through a biochemical reaction process. Therefore, people need to pay attention to their harmful 
166 effects on human health and environmental impact on aquatic ecosystem (Waalkes 2000; Wang

167 et al. 2017; Wu et al. 2009a). Therefore, to facilitate the determination of appropriate

168 management measures, the toxicity of heavy metals in the water system is worth studying

169 (Lemly 1996). In this study, hazard quotient (HQ) and hazard index (HI) were used to assess the

170 health risk of heavy metals in rivers of Wuhan (Meng et al. 2016). Heavy metals in the water

171 environment enter human body mainly through direct ingestion and dermal absorption (Giri \&

172 Singh 2014; Zeng et al. 2019). HQ is estimated by the ratio of exposure to reference dose (RfD)

173 in various pathways. HI is the sum of the HQs of the two main exposure pathways mentioned

174 above, which can be used to represent the total potential non-carcinogenic risk of individual

175 heavy metals. When $\mathrm{HQ} / \mathrm{HI}$ is greater than 1 , the pollution level may cause harm to human

176 health, and there is a non-carcinogenic risk, which needs particular attention; however, when

$177 \mathrm{HQ} / \mathrm{HI}$ is less than 1, there is no health risk (Tripathee et al. 2016; Yi et al. 2011). The

178 calculation formula of HQ and HI is as follows:

179

180

181

182

183

$$
\mathrm{ADD}_{\text {ingestion }}=\left(\mathrm{C}_{\mathrm{w}} \times \mathrm{IR} \times \mathrm{EF} \times \mathrm{ED}\right) /(\mathrm{BW} \times \mathrm{AT})
$$

$$
\begin{aligned}
& \mathrm{ADD}_{\text {dermal }}=\left(\mathrm{C}_{\mathrm{w}} \times \mathrm{SA} \times \mathrm{K}_{\mathrm{p}} \times \mathrm{ET} \times \mathrm{EF} \times \mathrm{ED} \times 10^{-3}\right) /(\mathrm{BW} \times \mathrm{AT}) \\
& \mathrm{HQ}=\mathrm{ADD} / \mathrm{RfD} \\
& \mathrm{RfD}_{\text {dermal }}=\mathrm{RfD} \times \mathrm{ABS}_{\mathrm{GI}} \\
& \mathrm{HI}=\sum \mathrm{HQs}
\end{aligned}
$$

184

185 Where $\mathrm{ADD}_{\text {ingestion }}$ is the average daily doses of direct intake $\left(\mu \mathrm{g} / \mathrm{kg} /\right.$ day); $\mathrm{ADD}_{\text {dermal }}$ is the average daily doses of skin absorption $\left(\mu \mathrm{g} / \mathrm{kg} /\right.$ day); $\mathrm{C}_{\mathrm{w}}$ is the concentration of heavy metals in each water sample $(\mu \mathrm{g} / \mathrm{L})$; IR is the ingestion rate $(\mathrm{L} /$ day); $\mathrm{EF}$ is the exposure frequency (days/year); ED is the exposure duration (years); AT is the average time (days); BW is the average body weight for adults and children $(\mathrm{kg})$; ET is the daily exposure time (h/day); SA is the area of skin exposure $\left(\mathrm{cm}^{2}\right) ; K_{p}$ is the dermal permeability coefficient in water $(\mathrm{cm} / \mathrm{h})$; RfD is the corresponding reference dose $\left(\mu \mathrm{g} / \mathrm{kg} /\right.$ day); $\mathrm{ABS}_{\mathrm{GI}}$ is the gastrointestinal absorption factor (dimensionless). The values of these parameters come from (US EPA \& Assessment 2009; Wang et al. 2017; Wu et al. 2009b). The carcinogenic risk of heavy metals is evaluated by Eq. (9). Carcinogenic risk represents the increased probability of cancer due to chemical exposure (Chen \& Liao 2006; Obiri et al. 2006). CR values in US-EPA are divided into three levels: (1) CR value less than $10^{-6}$ indicates 
198 negligible level; (2) $10^{-6}<\mathrm{CR}<10^{-4}$ is acceptable level; (3) $\mathrm{CR}>10^{-4}$ indicates high cancer risk 199 to human (Qu et al. 2018).

$$
\left\{\begin{array}{cc}
\mathrm{CR}=\mathrm{ADD} \times \mathrm{SF}, & \mathrm{ADD} \times \mathrm{SF}<0.01 \\
\mathrm{CR}=1-\mathrm{EXP}(-\mathrm{ADD} \times \mathrm{SF}), & \mathrm{ADD} \times \mathrm{SF} \geq 0.01
\end{array}\right.
$$

201

In this study, carcinogenic and non-carcinogenic risk assessments were performed for As, which was carcinogenic to humans. For the other eight heavy metals (V, Mn, Fe, Co, Ni, Zn, Mo, Sb), only non-carcinogenic risk assessments were considered. The HI and CR values of the sampling points were interpolated into the surface rivers of Wuhan by the IDW method to show the spatial distribution of non-carcinogenic risk and carcinogenic risk.

\section{Results}

\section{Kolmogorov-Smirnov test of data}

210 The normal distribution of the data in this study was tested by Kolmogorov-Smirnov (K-S)

211 statistics (Table 1). Results indicated that only vanadium and dissolved oxygen were normal

212 distribution. It could be seen from the test results that the average concentration of heavy metals

213 might be seriously affected by the abnormal values of water samples. Therefore, the median

214 concentrations were used for calculation. However, arithmetic means were used for comparison

215 because the values in the drinking water standards are generally given as arithmetic means.

216

\section{Physicochemical characteristics}

218 The water quality parameters ( $\mathrm{pH}, \mathrm{EC}, \mathrm{DO})$ of water samples are exhibited in Table 1. The $\mathrm{pH}$

219 value of the river water ranged from 5.51 to 9.14 , with a mean of 7.96, demonstrating slight

220 alkalinity characteristics. The DO ranged from 2.59 to $19.24 \mathrm{mg} / \mathrm{L}$, with a mean of $7.75 \mathrm{mg} / \mathrm{L}$.

221 The EC ranged from 213.0 to $661.0 \mu \mathrm{S} / \mathrm{cm}$, with a mean of $344.0 \mu \mathrm{S} / \mathrm{cm}$. In a word, pH, EC and

222 DO had pronounced variability in rivers in Wuhan.

223

\section{Concentrations of heavy metals in river water}

225 The concentrations of dissolved heavy metals in rivers in Wuhan are demonstrated in Table 1. V, $226 \mathrm{Fe}, \mathrm{Ni}, \mathrm{Zn}, \mathrm{As}$, Mo and Sb had relatively high concentration, with mean concentrations of

$2271.91 \mu \mathrm{g} / \mathrm{L}, 12.80 \mu \mathrm{g} / \mathrm{L}, 1.16 \mu \mathrm{g} / \mathrm{L}, 2.10 \mu \mathrm{g} / \mathrm{L}, 3.72 \mu \mathrm{g} / \mathrm{L}, 2.28 \mu \mathrm{g} / \mathrm{L}, 4.29 \mu \mathrm{g} / \mathrm{L}$, respectively.

228 Moreover, there were a few elements whose concentration was less than $1 \mu \mathrm{g} / \mathrm{L}$, represented by $229 \mathrm{Mn}(0.90 \mu \mathrm{g} / \mathrm{L})$ and $\mathrm{Co}(0.06 \mu \mathrm{g} / \mathrm{L})$. Fe, Sb and As were the most abundant metals in sampling 230 periods. 
231

232 Concentrations of dissolved heavy metals were compared with the limits of the Chinese drinking

233 water guideline (2006), WHO (2011), US EPA (2003) and the Chinese surface water standard

234 (2002) (Table 2). The total concentration ( average ) of all heavy metals in river water was within

235 the three drinking water standard limits (except V, there is no corresponding standard). The

236 concentrations of $\mathrm{Zn}$ and As belonged to Grade I of surface water standard, which indicated that

237 the overall water quality of the Wuhan river water was excellent. However, Sb concentrations in

238 YR and HR exceeded the limit values of the three drinking water standards and in FR was close

239 to the limit. In addition, the As concentrations in DJR and QLR were significantly higher than

240 those in other rivers, which were close to the standard limits of drinking water. These heavy

241 metals exceeded or closed to guideline values could be considered as pollutants, which might be

242 caused by relatively high anthropogenic input at the corresponding sampling points. For

243 example, Sb concentration in HR and As concentration in QLR were higher than the drinking

244 water guideline, which indicated that the two rivers were significantly affected by anthropogenic 245 input.

246

247 Table S1 shows the comparison of some heavy metals in rivers in Wuhan with other rivers in the 248 world. Except for Mn, Fe, and Co, the average concentrations of heavy metals were higher than 249 the world average. The average heavy metals in rivers in Wuhan were lower than other rivers in 250 China, such as Xiangjiang (Zeng et al. 2015), Dan River (Meng et al. 2016), Tarim River (Xiao 251 et al. 2014), Zhujiang River (Zeng et al. 2019), and Huai River (Wang et al. 2017). The heavy

252 metals concentrations in some developing countries were generally higher than in this study,

253 such as Vietnam, Iran, Nigeria, India and Turkey (Eneji et al. 2012; Giri \& Singh 2014;

254 Nasrabadi 2015; Thuong et al. 2013; Varol \& Şen 2012). However, in this study, the average

255 heavy metals were higher than in some developed countries, such as the USA, France, Australia,

256 Canada (Elbaz-Poulichet et al. 2006; Gaillardet et al. 2014; Markich \& Brown 1998; Warnken \&

257 Santschi 2009). This showed that the pollution level of heavy metals in rivers in Wuhan was at a

258 medium level.

259

260 Spatial distribution of heavy metals

261 Spatial distribution of heavy metals in the main stream

262 The spatial distribution of heavy metals in the main stream is presented in Fig. 2. In general, Fe,

$263 \mathrm{Mn}$ and Co concentrations presented a slowly increasing trend from upstream to downstream. In

264 contrast, V, Ni, Mo, Zn, As, Sb increased slowly from upstream to downstream and then 
265 decreased gradually at YR-7. It should be noted that V, Ni, Zn, As and Sb concentrations were

266 higher at YR-7, and Mn, Fe and Mo concentrations were higher at YR-4 and YR-6, while the

267 fluctuation of Co along the main stream was not apparent. Different distribution of nine heavy

268 metals might be affected by various local human activities, like industrial, agricultural, domestic,

269 etc..

270

271 Spatial distribution of heavy metals in tributaries

272 The spatial distribution of each heavy metal in tributaries is exhibited in Fig. 3. The

273 concentrations of heavy metals in QLR, XSR, HR and FR were relatively high, while those in

274 DJR, SSR and DSR were relatively low. Although the spatial distribution showed wide variation,

275 according to the spatial distribution characteristics of heavy metals, we could conclude three

276 main distribution patterns: (1) the V, Zn and Sb concentrations in HR were higher than those in

277 other rivers; (2) the Co, Fe, Mn, Ni and Mo concentrations in XSR were higher; (3) The

278 concentration of As in QLR and DJR was higher. In addition, it was noteworthy that all heavy

279 metals at FR-3 showed a solid upward trend, which might be related to the effluent of the Hanxi

280 wastewater treatment plants upstream of the sampling point.

281

\section{Statistical analysis}

283 Correlation matrix can show the correlation between survey variables by presenting the overall

284 consistency of the data set (Chen et al. 2007; Helena 2000; Wang et al. 2017). In this study, to

285 identify the likely sources of heavy metals in the rivers of Wuhan, Spearman's correlation

286 analysis method was used to initially determine the degree of correlation between nine dissolved

287 heavy metals. The results are shown in Fig. 4. Mn, Fe, Co, Ni and Mo were positively correlated,

288 and the correlation coefficients ranged from 0.15 to 0.73 . A significant positive correlation was

289 observed between $\mathrm{V}$ and $\mathrm{Sb}(\mathrm{p}<0.01)$. In addition, Mo was also significantly positively correlated

290 with V (0.47) and As (0.37).

291

292 The application of PCA can more accurately identify the sources of these heavy metals (Dong et

293 al. 2015; Kumar et al. 2017). According to the Kaiser-Meyer-Olkin (KMO) value (0.73) and

294 Bartlett's sphericity test (zero) results, the data in this study could be analyzed by PCA (Varol

295 2011). Three principal components (PC) with eigenvalues $>1$ (eigenvalue of 3.74 for PC1; 2.11

296 for PC2; and 1.19 for PC3) were extracted, explaining approximately $78.27 \%$ of the total

297 variance. Three PCs were presented in table 3 and Fig. 5. In PC1, the load of Mn (0.76), Fe

298 (0.75), Co (0.92), Ni (0.88) and Mo (0.58) was higher, which explained the variance of 35.25\%. 
299 The PC2 explained $25.81 \%$ of the total variance, mainly including V (0.80), Zn (0.78) and Sb

300 (0.84). Finally, As (0.84) and Mo (0.66) had a high load in PC3, accounting for $17.21 \%$ of the

301 total variance.

302

303 Discussion

304 Controlling factors for dissolved heavy metals

305 The content of dissolved heavy metals in water is controlled by many factors, such as $\mathrm{pH}$, EC

306 and lithology (Gao et al. 2020; Xu et al. 2020b). The competition of relative binding sites

307 between metal and hydrogen ions is affected by $\mathrm{pH}$ (Papafilippaki et al. 2008). The lower the $\mathrm{pH}$

308 value, the more intense the competition. Moreover, the lower $\mathrm{pH}$ may dissolve metal complexes

309 in sediments, thereby releasing free metal ions (Gao et al. 2020). However, in this study, pH was

310 only significantly positively correlated with $\mathrm{Co}(0.365)(\mathrm{P}<0.05)$, but was no correlation with

$311 \mathrm{~V}, \mathrm{Mn}, \mathrm{Fe}, \mathrm{Ni}, \mathrm{Zn}, \mathrm{As}$, Mo and $\mathrm{Sb}$ (Fig. 4). Therefore, $\mathrm{PH}$ is not the primary control factor of

312 dissolved heavy metal content in the study area. EC can measure the total dissolved metal ions in

313 water and reflect the biogeochemistry and land use (Walker \& Pan 2006). Higher EC may lead to

314 increased dissolved heavy metals in water (Gao et al. 2020). As shown in Fig. 4, EC was

315 significantly positively correlated with $\mathrm{Mn}$ (0.557), Fe (0.757), Co (0.485), Ni (0.381), As

316 (0.531) and Mo (0.845). The results showed that EC played an essential role in the content of

317 dissolved heavy metals in the river.

318

319 Rainfall is an important factor in controlling dissolved heavy metals in rivers (Li \& Zhang 2010).

320 Although it has a dilution effect in the rainy season, the amount of non-point source pollutants,

321 mine wastewater and geological materials generated by weathering entering rivers may increase

322 (Li \& Zhang 2010; Xu et al. 2020b). Temperature, rainfall and other factors will affect the

323 chemical weathering of rocks (Chen et al. 2020; Ma et al. 2020; Xu et al. 2020b; Zhong et al.

324 2017). In the rainy season, with the increase of river flow, chemostatic behavior is induced by

325 increasing the surface area of active minerals, which accelerates the rocks' weathering (Xu et al.

326 2020b; Zhong et al. 2017). Therefore, the release rate of dissolved heavy metals in carbonate

327 rocks will increase with the acceleration of rock weathering. In addition, under high flow

328 conditions, the solute concentrations produced by weathering of different rocks may be changed

329 by dilution due to the decrease of water-rock interaction time (Xu et al. 2020b; Zhong et al.

330 2017). In our study, the low concentrations of $\mathrm{Fe}, \mathrm{Mn}, \mathrm{Co}$, Ni and Mo could be attributed to the

331 dilution effect at high flow, which was speculated to be derived from natural processes. On the 
332 other hand, the relatively high concentrations of $\mathrm{V}, \mathrm{Zn}, \mathrm{Sb}$ and As could be considered the

333 increase of anthropogenic emissions under rainfall.

334

335 Potential source identification

336 The sources of heavy metals are diverse, and each element may have multiple sources. CA and

337 PCA were used to identify the sources of nine elements in our study.

338 CA mainly represented the correlation between two elements, and PCA can divide elements into

339 different arrays, which indicated different anthropogenic or natural sources of these elements

340 (Gao et al. 2020; Zeng et al. 2015). The higher factor explained the total variance, the higher

341 contribution of the source to the nine elements ( $\mathrm{Li}$ 2007). According to the CA and PCA results,

342 three categories could be identified for the dominant sources of 9 heavy metals in Wuhan.

343

344 Group 1 defined that Mn, Fe, Co, Ni and Mo were related (Fig. 4), which indicated that their

345 sources and behavior might originate similarly. Mn, Fe, Co, Ni and Mo presented a robust

346 positive loading in PC1 (Fig. 5). Fe was the central element in the earth's crust and Mn, Co, Ni

347 and Mo mainly originated from rock weathering and soil-forming processes (Li \& Zhang 2010;

348 Xiao et al. 2019; Yokoo et al. 2004). Combined with significantly lower Mn, Fe and Co

349 concentrations than the world average, we attributed group 1 to the geological source of the

350 basin.

351

352 As shown in Table 3, V, Zn and Sb presented a strong loading in PC2 (loading values $>0.75$ )

353 (Zeng et al. 2020). V and Sb presented a significant positive correlation in Fig. 4. Moreover, V,

$354 \mathrm{Zn}$ and $\mathrm{Sb}$ presented the same spatial distribution pattern among rivers, such as the

355 concentrations of $\mathrm{V}, \mathrm{Zn}$ and $\mathrm{Sb}$ in $\mathrm{HR}$ affected by human activities were significantly higher than

356 those in other rivers ( Wu et al. 2019). A study in 2010 found that the concentrations of $\mathrm{V}$ and $\mathrm{Sb}$

357 were high in the upper HR, which was attributed to the input of human activities (Li \& Zhang

358 2010). Other studies showed that V, Zn and Sb were widely used in industry (Gao et al. 2020;

359 Kravchenko et al. 2014). Therefore, though the three elements had their natural sources, we

360 inferred that industrial emissions were the dominant factor for $\mathrm{V}, \mathrm{Zn}$ and $\mathrm{Sb}$ in group 2.

361

362 Group 3 mainly contained As and Mo. These two metals were the main contributors to PC3 (Fig.

363 5) and presented a significant positive correlation (Fig. 4). The concentration of As was higher in

364 QLR, DJR and XSR. QLR and XSR were located in the main urban area of Wuhan, and the high

365 concentration of As might be related to urban activities. The DJR was located in the middle and

Peer] reviewing PDF | (2021:04:60018:1:1:NEW 30 Jun 2021) 
366 lower reaches of the Yangtze River, with many plains and higher agricultural activities than

367 other areas, so soil erosion caused by farming might be another important reason for the increase

368 of As concentration in the water body (Wu et al. 2019). The concentration of Mo was also higher

369 in QLR and XSR, so Mo might mainly be human input of urban activities. Previous studies

370 showed that Mo was widely used in electronics, medicine and agriculture (Elbaz-Poulichet et al.

371 2006; Liang 2020). Therefore, we attributed group 3 to the mixed input of urban and agricultural

372 activities.

373

374 As described in the above analysis, Mn, Fe, Co and Ni were natural sources, while V, Zn, As and

$375 \mathrm{Sb}$ were mainly anthropogenic sources. It was worth noting that Mo was present in group 1 and

376 group 3 simultaneously, which indicated that the natural process and human activities influenced

377 the change of Mo in water.

378

379

\section{Spatial distribution of heavy metal pollution index (HPI)}

380

In this study, HPI was used for describing the potential environmental risks of heavy metals in

381 water. It calculated the spatial trend of the HPI based on nine heavy metals in the rivers (Fig. 6).

382 HPI ranged from 23.74 to 184.0 . The HPI values of all sampling points belonged to a high level (HPI > 30), except for the two sampling points of Daoshui River. The results showed that the ecological problems of heavy metals in river water were widespread (Tiwari et al. 2015). In addition, the contribution of $\mathrm{Zn}$ in the evaluation of HPI of rivers in Wuhan was not significant because of its lower weightage (Wi) value. Heavy metals such as Mn, Fe, Ni, As, Mo and Sb had higher weightage (Wi) values and higher HPI values, indicating that the higher concentration of these heavy metals in river water, the worse water quality (Bhaskar et al. 2020). It should be noted that As and Sb contribute most of the HPI values, which was consistent with their higher concentrations in the river. The spatial distribution of HPI values showed that the ecological risk of heavy metals around HR-2 was the highest, and the HPI value of this point was 184.0, which exceeded the value of 100, which was the critical pollution index value (Bhaskar et al. 2020). Overall, except for DSR-1 and DSR-2 sites, the ecological risk of heavy metals in all sampling sites was a severe problem. It might be due to industrial, agricultural and domestic activities (Wang et al. 2017).

\section{Human health risk assessment}


400

401

402

403

404

405

406

407

408

409

410

411

412

413

414

415

416

417

418

419

420

421

422

423

424

425

426

427

428

429

430

431

432

433

than the threshold 1 we considered in this study for both adults and children. Results presented that the harm of nine heavy metals in rivers of Wuhan to residents was low. Moreover, we observed that children had higher $\mathrm{HQ}_{\text {ingestion }}$ and $\mathrm{HQ}_{\text {dermal }}$ than adults, indicating that heavy metals were more harmful to children. It was worth noting that the HI values of $\mathrm{Sb}$, As and $\mathrm{V}$ were at least one order of magnitude higher than other heavy metals. Therefore, human health monitoring and environmental supervision agencies should pay special attention to the sources and exposure routes of $\mathrm{Sb}, \mathrm{As}$ and $\mathrm{V}$ in rivers in Wuhan.

The $\mathrm{HI}$ values of $\mathrm{V}$ and $\mathrm{Sb}$ and the $\mathrm{CR}$ values of $\mathrm{As}$ and their spatial distribution are shown in Table 5 and Fig. 7. For adults and children, the order of HI values of $\mathrm{V}$ in the rivers was $\mathrm{HR}>\mathrm{QLR}>\mathrm{FR}>\mathrm{XSR}>\mathrm{YR}>\mathrm{DJR}>\mathrm{SSR}>\mathrm{DSR}$, and the high-risk areas were HR, QLR, FR and $\mathrm{XSR}$. The order of HI values of $\mathrm{Sb}$ was $\mathrm{YR}>\mathrm{HR}>\mathrm{FR}>\mathrm{SSR}>\mathrm{XSR}>\mathrm{QLR}>\mathrm{DSR}>\mathrm{DJR}$, and the high-risk areas were YR, HR, FR and SSR. In addition, the HI value in YR (0.843 for children), HR (0.808 for children) and FR (0.732 for children) were relatively close to 1 . Therefore, Sb might have potential non-carcinogenic to human health, especially in the areas around the HR-2, YR-6, YR-7 and FR-3 (Fig. 7a, Fig. 7b). The HI value of As for children in QLR exceeded threshold 1, and that of adults was relatively close to 1 . Moreover, the HI values of As in DJR ( 0.586 for adults, 0.886 for children) were relatively close to 1 .Therefore, As might have potential non-carcinogenic risk to adults and children in these areas. The order of CR value of As in the rivers was $\mathrm{QLR}>\mathrm{DJR}>\mathrm{XSR}>\mathrm{HR}>\mathrm{FH}>\mathrm{YR}>\mathrm{SSR}>\mathrm{DSR}$. The $\mathrm{CR}$ values of As all exceeded the target risk $\left(10^{-4}\right)$ (Chen \& Liao 2006; Qu et al. 2018), which indicated that the carcinogenic risk of As to adults and children was widespread in the study area. Spatially, the areas around QLR-1 and DJR-1 have the highest risk (Fig. 7c, Fig. 7d). These findings deserve our grave concern about the carcinogenic effects of As in rivers in Wuhan.

According to the comprehensive results of the HI and CR index, the high-risk areas of rivers in Wuhan were summarized as follows: (1) As pollution was a significant threat to human health and the high-risk areas were QLR and DJR. (2) The high-risk areas of V were HR, QLR, FR and XSR, especially in HR, QLR-1 and XSR-1. (3) The high-risk areas of Sb were YR, HR and FR, especially in YR-6, YR-7 and HR-2.

According to the risk assessment results, As and $\mathrm{Sb}$ were the primary pollutants in rivers in Wuhan, which were consistent with the comparison results of drinking water standards (Table 2). The side effects of heavy metals have been widely reported, such as V has a toxic impact on the 
434 human digestive system, blood, nervous system and immune system (Chlubek et al. 2012; Rawal

435 et al. 1997). Sb may cause discomforts such as nausea, vomiting, anorexia, abdominal pain and

436 gastric ulcer (Saerens et al. 2019; Sundar \& Chakravarty 2010). Moreover, excessive As intake

437 may cause cancers (liver cancer, lung cancer, bladder cancer) and other side effects

438 (hypertension, neuropathy, diabetes, tibial disease) (Wu et al. 2009b; Xu \& Wang 2020).

439 Therefore, we should pay special attention to the potential non-carcinogenic risk of $\mathrm{V}$ and $\mathrm{Sb}$ and

440 the potential carcinogenic risk of As. It is necessary to take relevant measures to prevent

441 excessive heavy metals from entering rivers, and maintain a healthy water ecosystem and

442 provide water resources guarantee for the economic development of Wuhan.

443

444 However, there was uncertainty in the description of health risks for heavy metals, which had

445 been pointed out by US EPA and other relevant studies (Qu et al. 2018; US EPA \& Assessment

446 2009; Wu et al. 2009b). Water and skin contact factor $\left(\mathrm{K}_{\mathrm{p}}\right)$, different exposure conditions caused

447 by different ages and receptors, temporal changes of pollutant concentration and daily water

448 intake cannot be quantified, which led to methodological uncertainty. Furthermore, the US EPA

449 is the primary source of parameters in this study, which might not apply to the Chinese.

450 Consequently, it is necessary to clarify the risk characteristics further and improve the risk

451 assessment method by investigating river risk levels in Wuhan.

452

\section{Conclusions}

454 The spatial distribution of dissolved heavy metals in Wuhan had great spatial heterogeneity.

455 Different distribution characteristics of dissolved heavy metals caused by human activities

456 (industrial, agricultural, domestic) in different regions of Wuhan. The results of CA and PCA

457 showed that $\mathrm{Mn}, \mathrm{Fe}, \mathrm{Co}, \mathrm{Ni}$ and Mo were attributed to the geological sources of the basin, and V,

$458 \mathrm{Zn}$ and $\mathrm{Sb}$ were controlled by industrial activities, while As was mainly dominated by the mixed

459 input of urban and agricultural activities.

460

461 In general, the concentrations of all heavy metals in Wuhan river water were within the standard

462 range of China's drinking water. However, $\mathrm{Sb}$ in YR and HR exceeded the drinking water

463 guidelines set by WHO, US EPA and China EPA, and As in DJR and QLR were close to the

464 three drinking water guidelines, which required special attention. The heavy metal pollution

465 index results showed that As and Sb contributed most of the HPI values, which was consistent

466 with high concentrations in the rivers, indicating that these two heavy metals' ecological risk was

467 high. Non-carcinogenic risk and carcinogenic risk of heavy metals were analyzed by HI and CR. 
468 The results showed that $\mathrm{V}$ and $\mathrm{Sb}$ had potential non-carcinogenic risk and As might have a

469 potential carcinogenic risk to adults and children in the study area, while As might have a

470 potential non-carcinogenic risk for children around QLR. The results showed that As and $\mathrm{Sb}$

471 were the primary pollutants in rivers in Wuhan. We should prevent them from damaging the

472 aquatic ecosystem and provide water resources guarantee for the economic development of

473 Wuhan. It is necessary to develop a long-term monitoring scheme for As and Sb, which can

474 effectively control and manage the $\mathrm{As}$ and $\mathrm{Sb}$ pollution in rivers in the corresponding areas.

475

476

477

478

479

480

481

482

483

484

485

486

487

488

489

490

491

492

493

494

495

496

497

498

499

500

501

502

503

504

\section{Acknowledgements}

The author thanks for the sample collection of Huipeng Jia and Yuanyi Shen and the analytical assistance of Shilin Gao.

\section{References}

Ali MM, Ali ML, Islam MS, and Rahman MZ. 2016. Preliminary assessment of heavy metals in water and sediment of Karnaphuli River, Bangladesh. Environmental Nanotechnology, Monitoring \& Management 5:27-35. 10.1016/j.enmm.2016.01.002

Antoniadis V, Shaheen SM, Boersch J, Frohne T, Laing GD, and Rinklebe JJJoEM. 2016. Bioavailability and risk assessment of potentially toxic elements in garden edible vegetables and soils around a highly contaminated former mining area in Germany. 186:192-200.

Bhaskar M, Dixit AK, Ojha KK, Dubey S, Singh A, and Abhishek A. 2020. The impact of anthropogenic organic and inorganic pollutants on the Hasdeo River Water Quality in Korba Region, Chhattisgarh, India. Bioinformation 16:332-340. 10.6026/97320630016332

Cameron H, Mata MT, and Riquelme C. 2018. The effect of heavy metals on the viability of Tetraselmis marina AC16-MESO and an evaluation of the potential use of this microalga in bioremediation. Peerj 6:e5295. 10.7717/peerj.5295

Chen B-B, Li S-L, Pogge von Strandmann PAE, Sun J, Zhong J, Li C, Ma T-T, Xu S, and Liu CQ. 2020. Ca isotope constraints on chemical weathering processes: Evidence from headwater in the Changjiang River, China. Chemical Geology 531. 10.1016/j.chemgeo.2019.119341

Chen K, Jiao JJ, Huang J, and Huang R. 2007. Multivariate statistical evaluation of trace elements in groundwater in a coastal area in Shenzhen, China. Environ Pollut 147:771-780. 10.1016/j.envpol.2006.09.002

Chen SC, and Liao CM. 2006. Health risk assessment on human exposed to environmental polycyclic aromatic hydrocarbons pollution sources. Sci Total Environ 366:112-123. 10.1016/j.scitotenv.2005.08.047 
505 Chlubek D, Gutowska I, Baranowska-Bosiacka I, and Korbecki J. 2012. Biochemical and medical

506 importance of vanadium compounds. Acta Biochimica Polonica 59.

$507 \quad 10.18388 / a b p .2012 \_2138$

508 Chowdhury S, Mazumder MAJ, Al-Attas O, and Husain T. 2016. Heavy metals in drinking water:

509

510

511

512

513

514

515

516

517

518

519

520

521

522

523

524

525

526

527

528

529

530

531

532

533

534

535

536

537

538

539

540

541

542

Occurrences, implications, and future needs in developing countries. Sci Total Environ 569-570:476-488. 10.1016/j.scitotenv.2016.06.166

Dong Z, Kang S, Qin X, Li X, Qin D, and Ren J. 2015. New insights into trace elements deposition in the snow packs at remote alpine glaciers in the northern Tibetan Plateau, China. Sci Total Environ 529:101-113. 10.1016/j.scitotenv.2015.05.065

Du W, Li A, Lu M, An K, and Fan J. 2014. Preliminary Health Risk Assessment of Heavy Metals in the Yangtze River of Wuhan Area. Environmental Science \& Technology 37:535-539.

Elbaz-Poulichet F, Seidel JL, Casiot C, and Tusseau-Vuillemin MH. 2006. Short-term variability of dissolved trace element concentrations in the Marne and Seine rivers near Paris. Sci Total Environ 367:278-287. 10.1016/j.scitotenv.2005.11.009

Eneji IS, Sha'Ato R, and Annune PA. 2012. An assessment of heavy metals loading in River Benue in the Makurdi metropolitan area in Central Nigeria. Environ Monit Assess 184:201-207. 10.1007/s10661-011-1959-0

Gaillardet J, Viers J, and Dupré B. 2014. Trace Elements in River Waters. Treatise on Geochemistry, 195-235.

Gao S, Wang Z, Wu Q, and Zeng J. 2020. Multivariate statistical evaluation of dissolved heavy metals and a water quality assessment in the Lake Aha watershed, Southwest China. Peerj 8. $10.7717 /$ peerj. 9660

Giri S, and Singh AK. 2014. Risk assessment, statistical source identification and seasonal fluctuation of dissolved metals in the Subarnarekha River, India. J Hazard Mater 265:305314. 10.1016/j.jhazmat.2013.09.067

Gong X, Xiao L, Zhao Z, Li Q, Feng F, Zhang L, and Deng Z. 2018. Spatial variation of polycyclic aromatic hydrocarbons (PAHs) in surface sediments from rivers in hilly regions of Southern China in the wet and dry seasons. Ecotoxicol Environ Saf 156:322-329. 10.1016/j.ecoenv.2018.03.004

Guan S, Meng H, and Zhou M. 2008. The Distribution and Growing Ruels of Karst in Wuhan. Urban Geotechnical Investigation \& Surveying:145-149.

Gupta M, and Srivastava PKJWI. 2010. Integrating GIS and remote sensing for identification of groundwater potential zones in the hilly terrain of Pavagarh, Gujarat, India. 35:233-245.

Han G, and Liu C-Q. 2004. Water geochemistry controlled by carbonate dissolution: a study of the river waters draining karst-dominated terrain, Guizhou Province, China. Chemical Geology 204:1-21. 10.1016/j.chemgeo.2003.09.009

Han G, Song Z, Tang Y, Wu Q, and Wang Z. 2019. Ca and Sr isotope compositions of rainwater from Guiyang city, Southwest China: Implication for the sources of atmospheric aerosols

Peer) reviewing PDF | (2021:04:60018:1:1:NEW 30 Jun 2021) 
543

544

545

546

547

548

549

550

551

552

553

554

555

556

557

558

559

560

561

562

563

564

565

566

567

568

569

570

571

572

573

574

575

576

577

578

579

580

and their seasonal variations

Atmospheric Environment

214. 10.1016/j.atmosenv.2019.116854

Helena B. 2000. Temporal evolution of groundwater composition in an alluvial aquifer (Pisuerga River, Spain) by principal component analysis. Water Research 34:807-816. 10.1016/s0043-1354(99)00225-0

Hu Y, Qi S, Wu C, Ke Y, Chen J, Chen W, and Gong X. 2012. Preliminary assessment of heavy metal contamination in surface water and sediments from Honghu Lake, East Central China. Frontiers of Earth Science 6:39-47. 10.1007/s11707-012-0309-z

Jiang H, Qin D, Chen Z, Tang S, Bai S, Mou ZJBoEC, and Toxicology. 2016. Heavy Metal Levels in Fish from Heilongjiang River and Potential Health Risk Assessment. 97:536-542.

Kowalkowski T, Zbytniewski R, Szpejna J, and Buszewski B. 2006. Application of chemometrics in river water classification. Water Res 40:744-752. 10.1016/j.watres.2005.11.042

Kravchenko J, Darrah TH, Miller RK, Lyerly HK, and Vengosh A. 2014. A review of the health impacts of barium from natural and anthropogenic exposure. Environ Geochem Health 36:797-814. 10.1007/s10653-014-9622-7

Krishna AK, Satyanarayanan M, and Govil PK. 2009. Assessment of heavy metal pollution in water using multivariate statistical techniques in an industrial area: a case study from Patancheru, Medak District, Andhra Pradesh, India. J Hazard Mater 167:366-373. 10.1016/j.jhazmat.2008.12.131

Krishnamurti G, Subashchandrabose SR, Megharaj M, and Naidu RJESPRI. 2015. Assessment of bioavailability of heavy metal pollutants using soil isolates of Chlorella sp. 22:88268832.

Kumar M, Ramanathan AL, Tripathi R, Farswan S, Kumar D, and Bhattacharya P. 2017. A study of trace element contamination using multivariate statistical techniques and health risk assessment in groundwater of Chhaprola Industrial Area, Gautam Buddha Nagar, Uttar Pradesh, India. Chemosphere 166:135-145. 10.1016/j.chemosphere.2016.09.086

Lemly AD. 1996. Evaluation of the hazard quotient method for risk assessment of selenium. Ecotoxicol Environ Saf 35:156-162. 10.1006/eesa.1996.0095

Li P. 2019. Analysis on black and odorous water treatment of Xunsi River in Wuhan. Energy conservation and environmental protection: 125 .

Li S, and Zhang Q. 2010. Risk assessment and seasonal variations of dissolved trace elements and heavy metals in the Upper Han River, China. J Hazard Mater 181:1051-1058. 10.1016/j.jhazmat.2010.05.120

Li X. 2007. Comparison and Application of Principal Component Analysis, Factor Analysis and Cluster Analysis. Journal of Shandong Institute of Education:23-26. 10.3969/j.issn.10082816.2007.06.006

Liang Y. 2020. Study on Removal of Heavy Metal Molybdenum in water by Precipitation Method. Henan Science \& Technology:130-132. 
581 Liu J, and Han GJWR. 2021. Tracing Riverine Particulate Black Carbon Sources in Xijiang River

582

583

584

585

586

587

588

589

590

591

592

593

594

595

596

597

598

599

600

601

602

603

604

605

606

607

608

609

610

611

612

613

614

615

616

617

618

Basin: Insight from Stable Isotopic Composition and Bayesian Mixing Model.

Loska K, and Wiechuła D. 2003. Application of principal component analysis for the estimation of source of heavy metal contamination in surface sediments from the Rybnik Reservoir. Chemosphere 51:723-733. 10.1016/s0045-6535(03)00187-5

Ma T, Weynell M, Li S-L, Liu Y, Chetelat B, Zhong J, Xu S, and Liu C-Q. 2020. Lithium isotope compositions of the Yangtze River headwaters: Weathering in high-relief catchments. Geochimica Et Cosmochimica Acta 280:46-65. 10.1016/j.gca.2020.03.029

Markich SJ, and Brown PL. 1998. Relative importance of natural and anthropogenic influences on the fresh surface water chemistry of the Hawkesbury-Nepean River, south-eastern Australia. Science of the Total Environment 217:201-230. 10.1016/s0048-9697(98)001880

Meng Q, Zhang J, Zhang Z, and Wu T. 2016. Geochemistry of dissolved trace elements and heavy metals in the Dan River Drainage (China): distribution, sources, and water quality assessment. Environ Sci Pollut Res Int 23:8091-8103. 10.1007/s11356-016-6074-x

Mohan SV, Nithila P, and Reddy SJ. 2008. Estimation of heavy metals in drinking water and development of heavy metal pollution index. Journal of Environmental Science and Health Part A: Environmental Science and Engineering and Toxicology 31:283-289. $10.1080 / 10934529609376357$

Nasrabadi T. 2015. An Index Approach to Metallic Pollution in River Waters. International Journal of Environmental Research 9:385-394.

Obiri S, Dodoo DK, Okai-Sam F, and Essumang DK. 2006. Cancer health risk assessment of exposure to arsenic by workers of AngloGold Ashanti-Obuasi gold mine. Bull Environ Contam Toxicol 76:195-201. 10.1007/s00128-006-0907-0

Papafilippaki AK, Kotti ME, and Stavroulakis GG. 2008. SEASONAL VARIATIONS IN DISSOLVED HEAVY METALS IN THE KERITIS RIVER, CHANIA, GREECE. Global Nest Journal 10:320-325.

Qu L, Huang H, Xia F, Liu Y, Dahlgren RA, Zhang M, and Mei K. 2018. Risk analysis of heavy metal concentration in surface waters across the rural-urban interface of the Wen-Rui Tang River, China. Environ Pollut 237:639-649. 10.1016/j.envpol.2018.02.020

Rawal SB, Singh MV, Salhan A, Selvamurthy W, Tyagi AK, and Kumar S. 1997. Influence of vanadium on acclimatization of humans to high altitude. Int J Biometeorol 40:95-98. $10.1007 / \mathrm{s} 004840050025$

Saerens A, Ghosh M, Verdonck J, and Godderis L. 2019. Risk of Cancer for Workers Exposed to Antimony Compounds: A Systematic Review. Int J Environ Res Public Health 16. 10.3390/ijerph16224474

Sundar S, and Chakravarty J. 2010. Antimony toxicity. Int J Environ Res Public Health 7:42674277. 10.3390/ijerph7124267

Peer] reviewing PDF | (2021:04:60018:1:1:NEW 30 Jun 2021) 
619 Thuong NT, Yoneda M, Ikegami M, and Takakura M. 2013. Source discrimination of heavy metals

620

621

622

623

624

625

626

627

628

629

630

631

632

633

634

635

636

637

638

639

640

641

642

643

644

645

646

647

648

649

650

651

652

653

654

655

in sediment and water of To Lich River in Hanoi City using multivariate statistical approaches. Environ Monit Assess 185:8065-8075. 10.1007/s10661-013-3155-x

Tiwari AK, De Maio M, Singh PK, and Mahato MK. 2015. Evaluation of Surface Water Quality by Using GIS and a Heavy Metal Pollution Index (HPI) Model in a Coal Mining Area, India. Bull Environ Contam Toxicol 95:304-310. 10.1007/s00128-015-1558-9

Tripathee L, Kang S, Sharma CM, Rupakheti D, Paudyal R, Huang J, and Sillanpaa M. 2016. Preliminary Health Risk Assessment of Potentially Toxic Metals in Surface Water of the Himalayan Rivers, Nepal. Bull Environ Contam Toxicol 97:855-862. 10.1007/s00128016-1945-x

US EPA OoSWER, Waste, and Assessment CR. 2009. Risk Assessment Guidance for Superfund (RAGS), Volume I: Human Health Evaluation Manual (Part E, Supplemental Guidance for Dermal Risk Assessment) Interim.

Varol M. 2011. Assessment of heavy metal contamination in sediments of the Tigris River (Turkey) using pollution indices and multivariate statistical techniques. J Hazard Mater 195:355-364. 10.1016/j.jhazmat.2011.08.051

Varol M, and Şen B. 2012. Assessment of nutrient and heavy metal contamination in surface water and sediments of the upper Tigris River, Turkey. Catena 92:1-10. 10.1016/j.catena.2011.11.011

Waalkes MP. 2000. Cadmium carcinogenesis in review. Journal of Inorganic Biochemistry 79:241-244. 10.1016/s0162-0134(00)00009-x

Walker CE, and Pan Y. 2006. Using Diatom Assemblages to Assess Urban Stream Conditions. Hydrobiologia 561:179-189. 10.1007/s10750-005-1613-3

Wanda EMM, Gulula LC, and Phiri G. 2012. Determination of characteristics and drinking water quality index in Mzuzu City, Northern Malawi. Physics and Chemistry of the Earth, Parts A/B/C 50-52:92-97. 10.1016/j.pce.2012.09.004

Wang J, Liu G, Liu H, and Lam PKS. 2017. Multivariate statistical evaluation of dissolved trace elements and a water quality assessment in the middle reaches of Huaihe River, Anhui, China. Sci Total Environ 583:421-431. 10.1016/j.scitotenv.2017.01.088

Warnken KW, and Santschi PH. 2009. Delivery of Trace Metals (Al, Fe, Mn, V, Co, Ni, Cu, Cd, $\mathrm{Ag}, \mathrm{Pb}$ ) from the Trinity River Watershed Towards the Ocean. Estuaries and Coasts 32:158-172. 10.1007/s12237-008-9088-x

WHO. 2011. Guidelines for Drinking-water Quality.In 4rd ed ed. Word Health Organization: Geneva.

Wu B, Zhang X, Zhang X, Yasun A, Zhang Y, Zhao D, Ford T, and Cheng S. 2009a. Semi-volatile organic compounds and trace elements in the Yangtze River source of drinking water. Ecotoxicology 18:707-714. 10.1007/s10646-009-0331-4

PeerJ reviewing PDF | (2021:04:60018:1:1:NEW 30 Jun 2021) 
656 Wu B, Zhao DY, Jia HY, Zhang Y, Zhang XX, and Cheng SP. 2009b. Preliminary risk assessment

657

658

659

660

661

662

663

664

665

666

667

668

669

670

671

672

673

674

675

676

677

678

679

680

681

682

683

684

685

686

687

688

689

690

691

692 of trace metal pollution in surface water from Yangtze River in Nanjing Section, China. Bull Environ Contam Toxicol 82:405-409. 10.1007/s00128-008-9497-3

Wu WT, Ran XB, Li JX, Wang H, Li ML, Liu J, and Zang JY. 2019. [Sources, Distribution, and Fluxes of Major and Trace Elements in the Yangtze River]. Huan Jing Ke Xue 40:49004913. 10.13227/j.hjkx.201903134

Xiao J, Jin Z, and Wang J. 2014. Geochemistry of trace elements and water quality assessment of natural water within the Tarim River Basin in the extreme arid region, NW China. Journal of Geochemical Exploration 136:118-126. 10.1016/j.gexplo.2013.10.013

Xiao J, Wang L, Deng L, and Jin Z. 2019. Characteristics, sources, water quality and health risk assessment of trace elements in river water and well water in the Chinese Loess Plateau. Sci Total Environ 650:2004-2012. 10.1016/j.scitotenv.2018.09.322

$\mathrm{Xu}$, and Wang. 2020. WUHAN WATER RESOURCES BULLETIN. http://swjwuhangoven/szy/202011/t20201126_1518840html.

$\mathrm{Xu} \mathrm{J}$, Zheng L, Xu L, Liu B, Liu J, and Wang X. 2020a. Identification of dissolved metal contamination of major rivers in the southeastern hilly area, China: distribution, source apportionment, and health risk assessment. Environ Sci Pollut Res Int 27:3908-3922. 10.1007/s11356-019-06774-8

Xu S, Lang Y, Zhong J, Xiao M, and Ding H. 2020b. Coupled controls of climate, lithology and land use on dissolved trace elements in a karst river system. Journal of Hydrology 591. 10.1016/j.jhydrol.2020.125328

Yang F, Hao Z, Zhang S, Liu H, Wang C, and Ling Q. 2016. Environment Geochemistry of Heavy Metals in the alluvial Soils of Yangtze River in Wuhan City. Acta Geologica Sinica 90:1955-1964.

Yi Y, Yang Z, and Zhang S. 2011. Ecological risk assessment of heavy metals in sediment and human health risk assessment of heavy metals in fishes in the middle and lower reaches of the Yangtze River basin. Environ Pollut 159:2575-2585. 10.1016/j.envpol.2011.06.011

Yokoo Y, Nakano T, Nishikawa M, and Quan H. 2004. Mineralogical variation of Sr-Nd isotopic and elemental compositions in loess and desert sand from the central Loess Plateau in China as a provenance tracer of wet and dry deposition in the northwestern Pacific. Chemical Geology 204:45-62. 10.1016/j.chemgeo.2003.11.004

Zaric NM, Deljanin I, Ilijevic K, Stanisavljevic L, Ristic M, and Grzetic I. 2018. Assessment of spatial and temporal variations in trace element concentrations using honeybees (Apis mellifera) as bioindicators. Peerj 6:e5197. 10.7717/peerj.5197

Zeng J, and Han G. 2020a. Preliminary copper isotope study on particulate matter in Zhujiang River, southwest China: Application for source identification. Ecotoxicol Environ Saf 198:110663. 10.1016/j.ecoenv.2020.110663

Peer) reviewing PDF | (2021:04:60018:1:1:NEW 30 Jun 2021) 
693 Zeng J, and Han G. 2020b. Tracing zinc sources with Zn isotope of fluvial suspended particulate 694 matter in Zhujiang River, southwest China. Ecological Indicators 118. $695 \quad$ 10.1016/j.ecolind.2020.106723

696 Zeng J, Han G, Wu Q, and Tang Y. 2019. Geochemical characteristics of dissolved heavy metals 697 in Zhujiang River, Southwest China: spatial-temporal distribution, source, export flux 698 estimation, and a water quality assessment. Peerj 7:e6578. 10.7717/peerj.6578

699 Zeng J, Han G, and Yang K. 2020. Assessment and sources of heavy metals in suspended 700 particulate matter in a tropical catchment, northeast Thailand. Journal of Cleaner $701 \quad$ Production 265. 10.1016/j.jclepro.2020.121898

702 Zeng X, Liu Y, You S, Zeng G, Tan X, Hu X, Hu X, Huang L, and Li F. 2015. Spatial distribution, 703 health risk assessment and statistical source identification of the trace elements in surface 704 water from the Xiangjiang River, China. Environ Sci Pollut Res Int 22:9400-9412. $705 \quad 10.1007 / \mathrm{s} 11356-014-4064-4$

706 Zhang Z, Lu Y, Li H, Tu Y, Liu B, and Yang Z. 2018. Assessment of heavy metal contamination, 707 distribution and source identification in the sediments from the Zijiang River, China. Sci 708 Total Environ 645:235-243. 10.1016/j.scitotenv.2018.07.026

709 Zhong J, Li SL, Tao F, Yue F, and Liu CQ. 2017. Sensitivity of chemical weathering and dissolved 710 carbon dynamics to hydrological conditions in a typical karst river. Sci Rep 7:42944. $711 \quad 10.1038 /$ srep42944

712 
Figure 1

Sample sites distribution of the studied rivers in Wuhan.

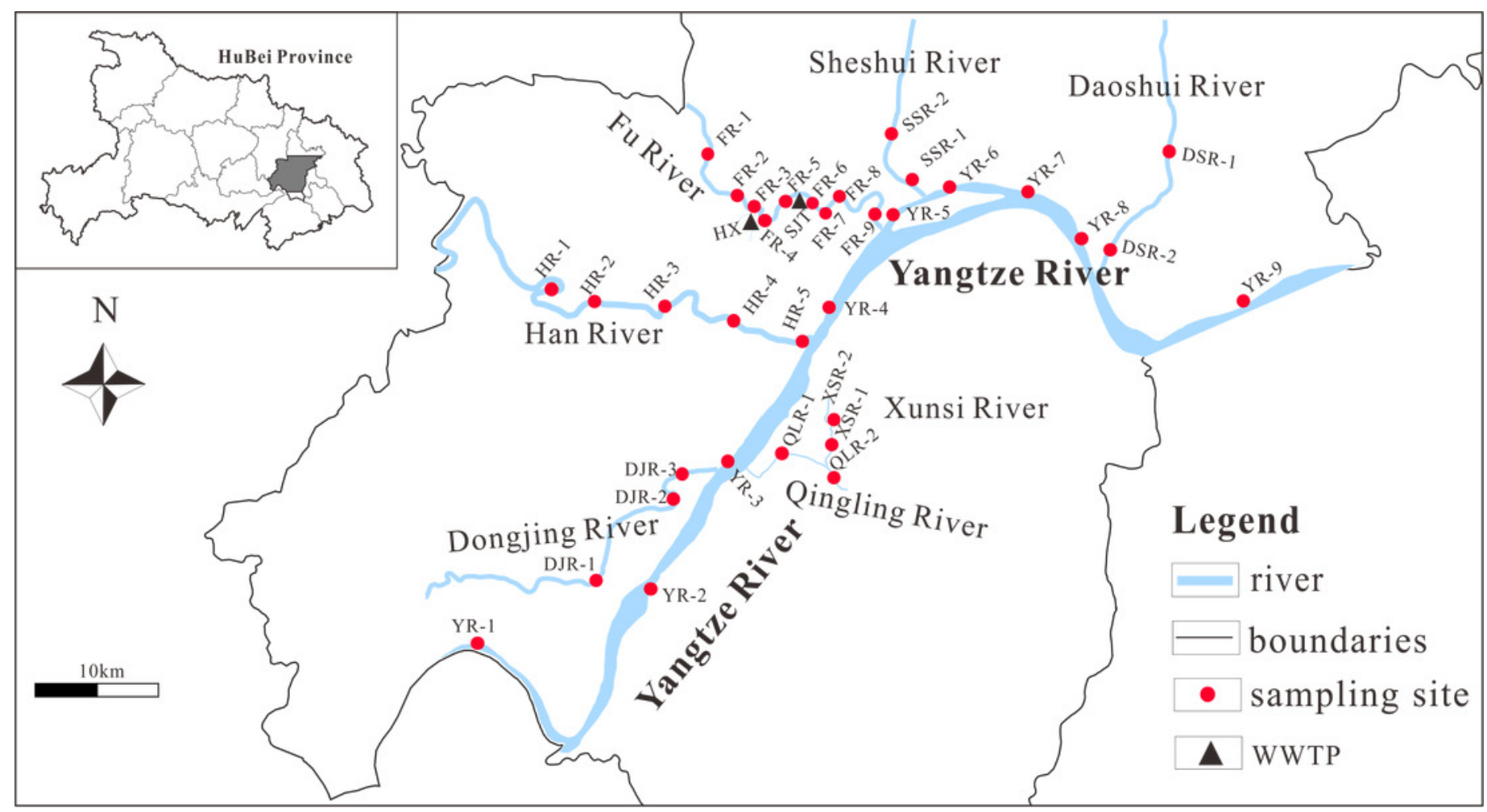


Figure 2

Spatial variations of nine heavy metals in nine sampling sites along the mainstream from Yangtze River in Wuhan.

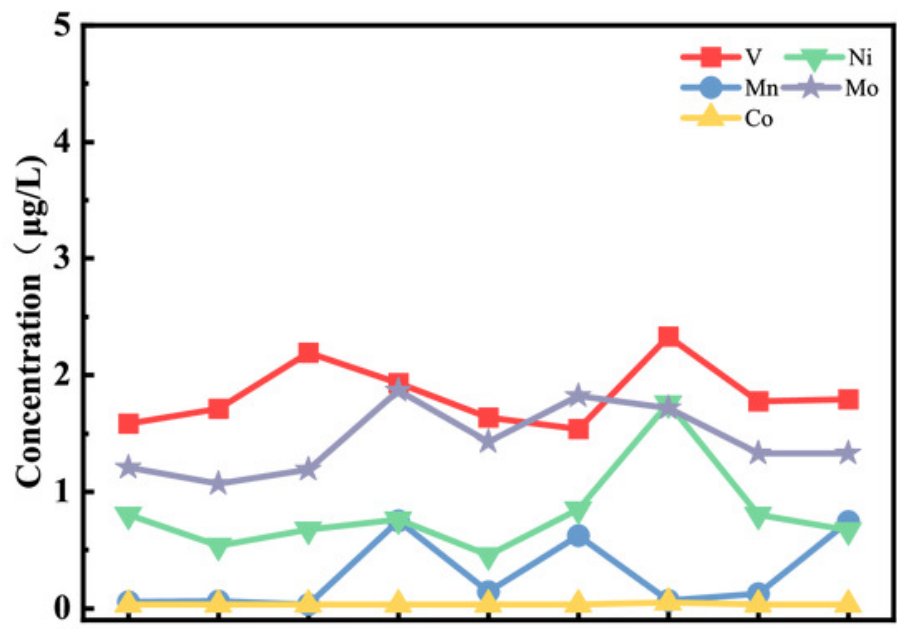

YR-1 YR-2 YR-3 YR-4 YR-5 YR-6 YR-7 YR-8 YR-9

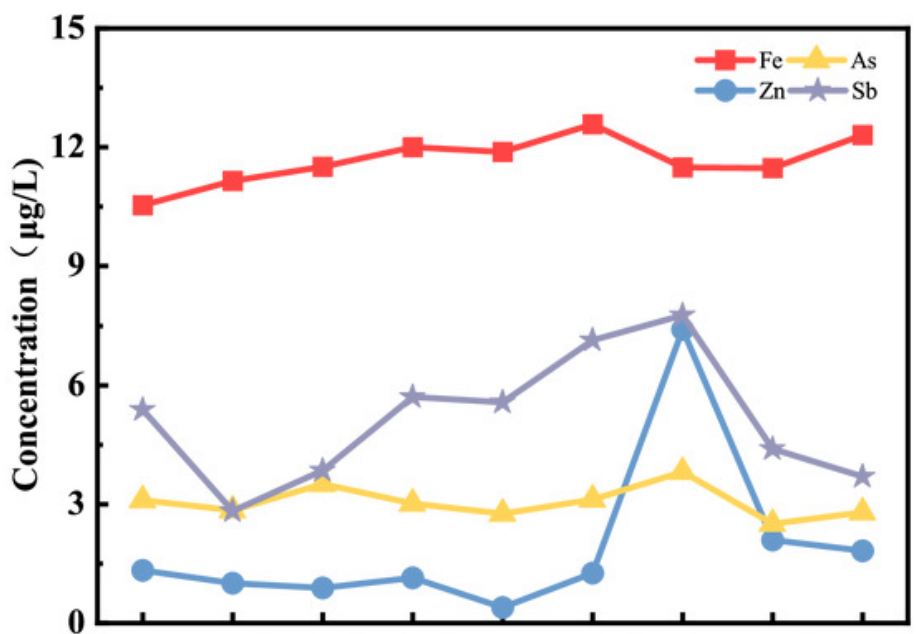

YR-1 YR-2 YR-3 YR-4 YR-5 YR-6 YR-7 YR-8 YR-9 
Figure 3

Spatial distribution of heavy metals in tributaries from Yangtze River in Wuhan.
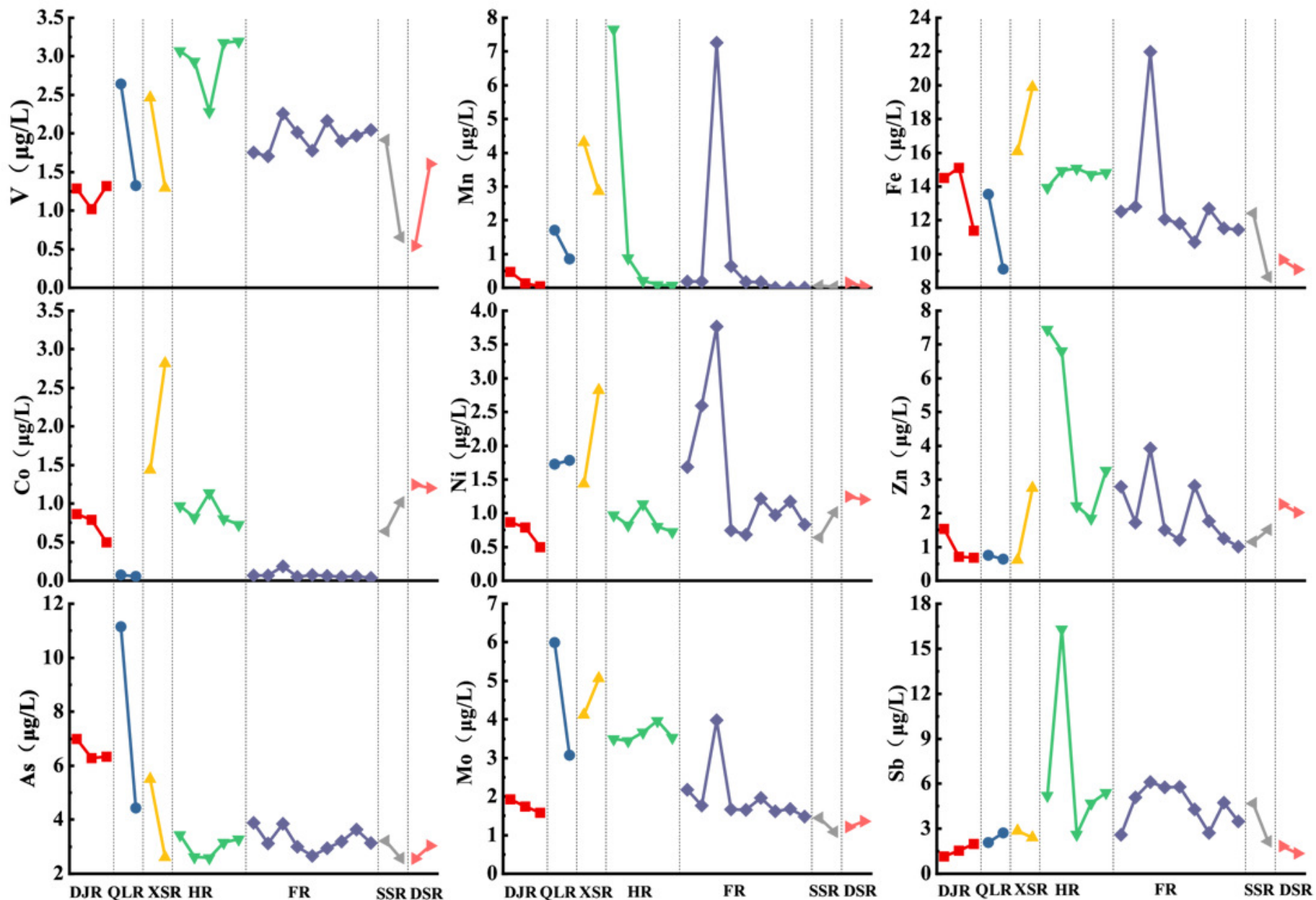
Figure 4

Correlation coefficients of heavy metals and physicochemical parameters $(\mathrm{pH}, \mathrm{EC}$ and DO) in rivers in Wuhan, $*$ denote $p<0.05$; $*$ denote $p<0.01$. 


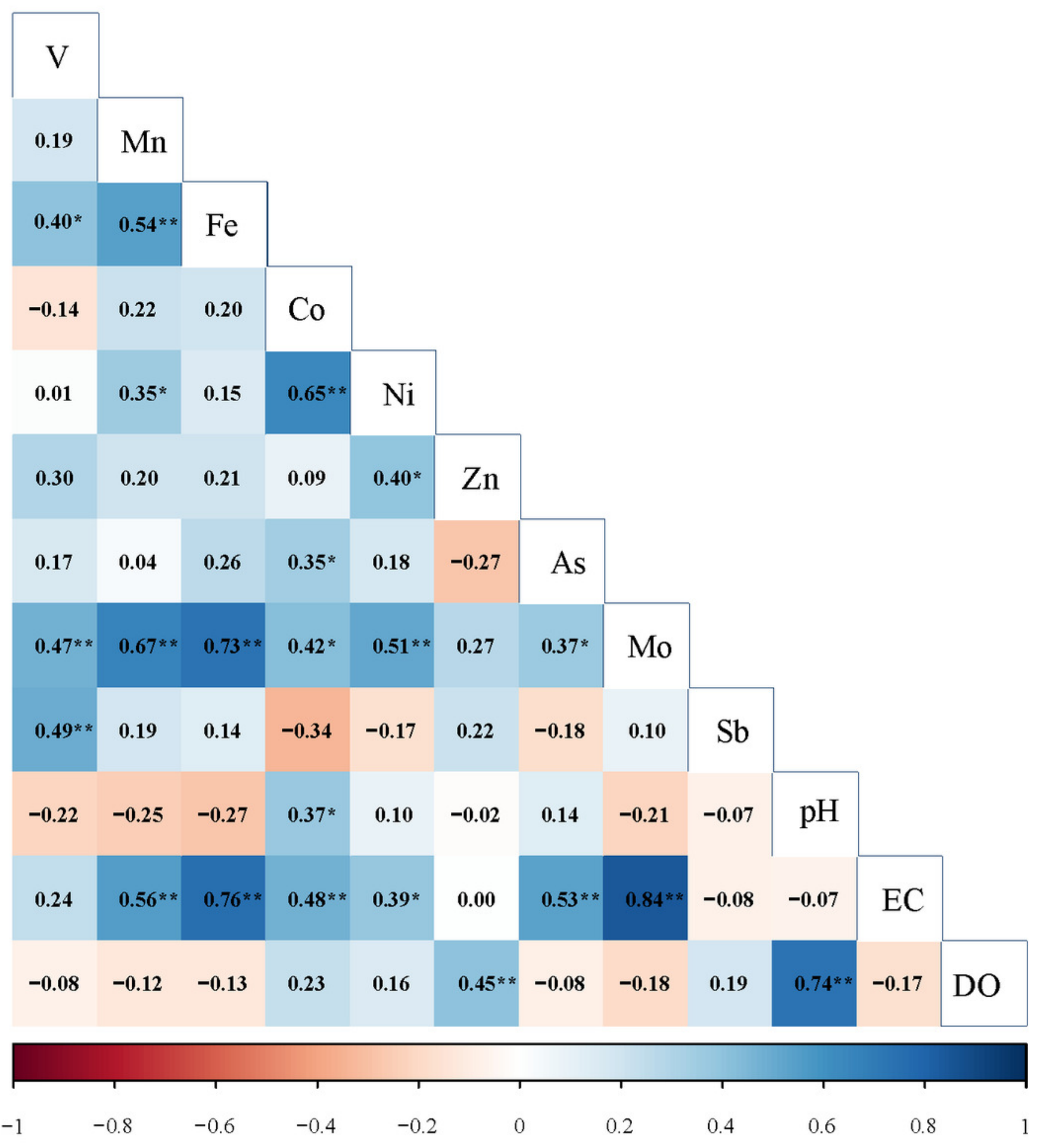


Figure 5

Loading plot of factors or dissolved heavy metals in rivers.

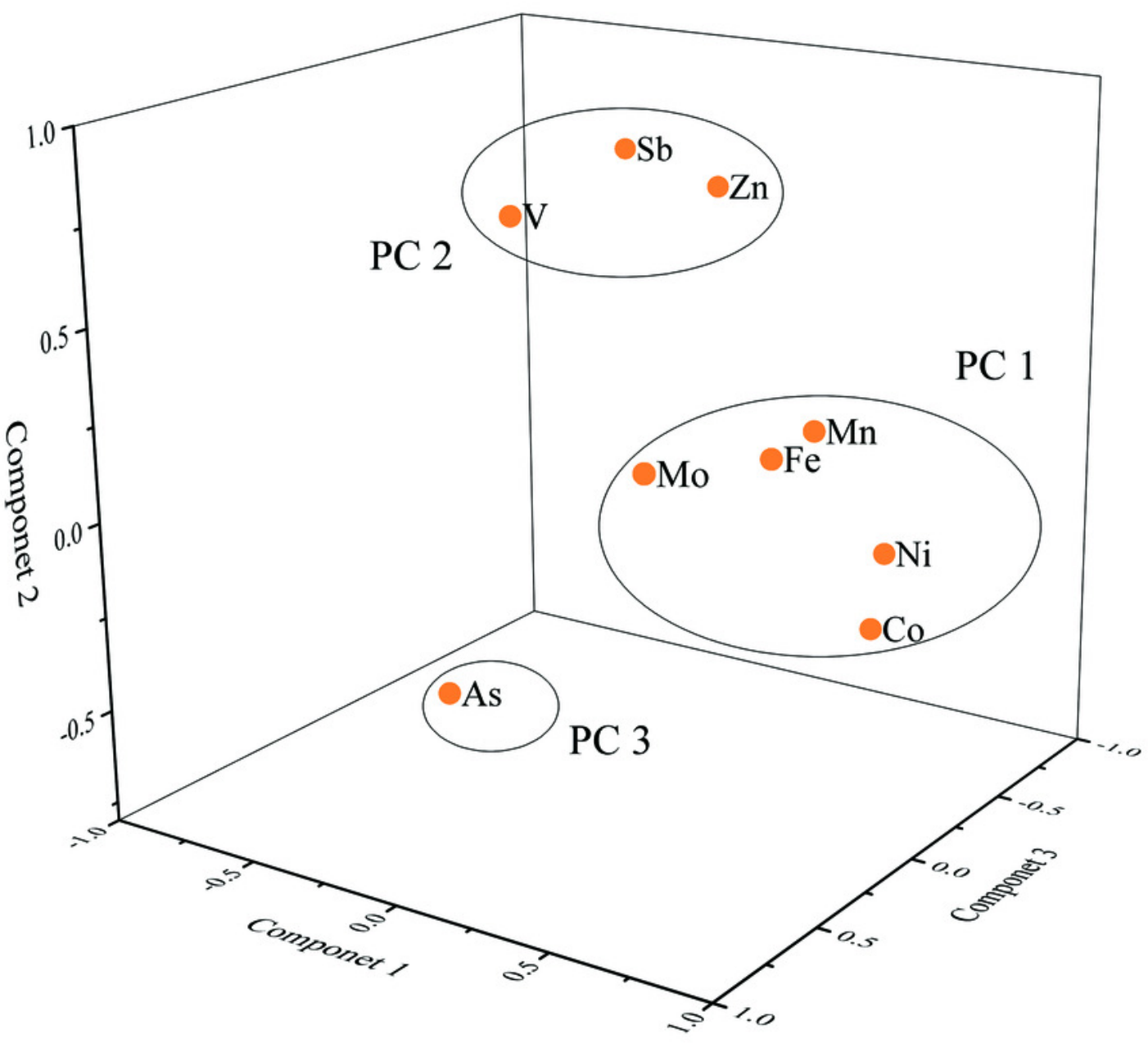


Figure 6

Spatial distribution of HPI.

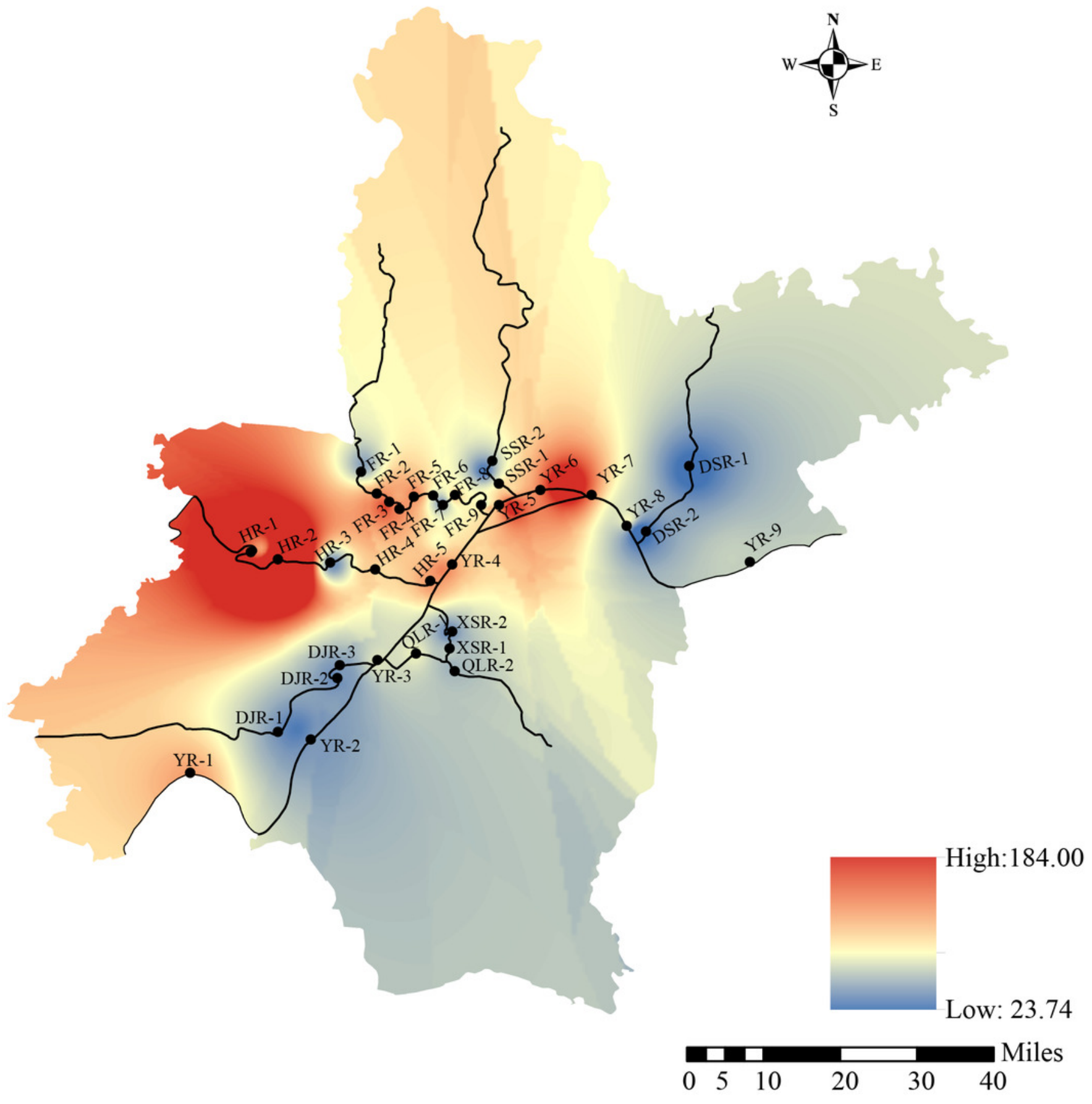




\section{Figure 7}

Spatial distribution of HI for Sb (a,b) and CR for As (c,d). (a), (c) Children; (b), (d) Adults.

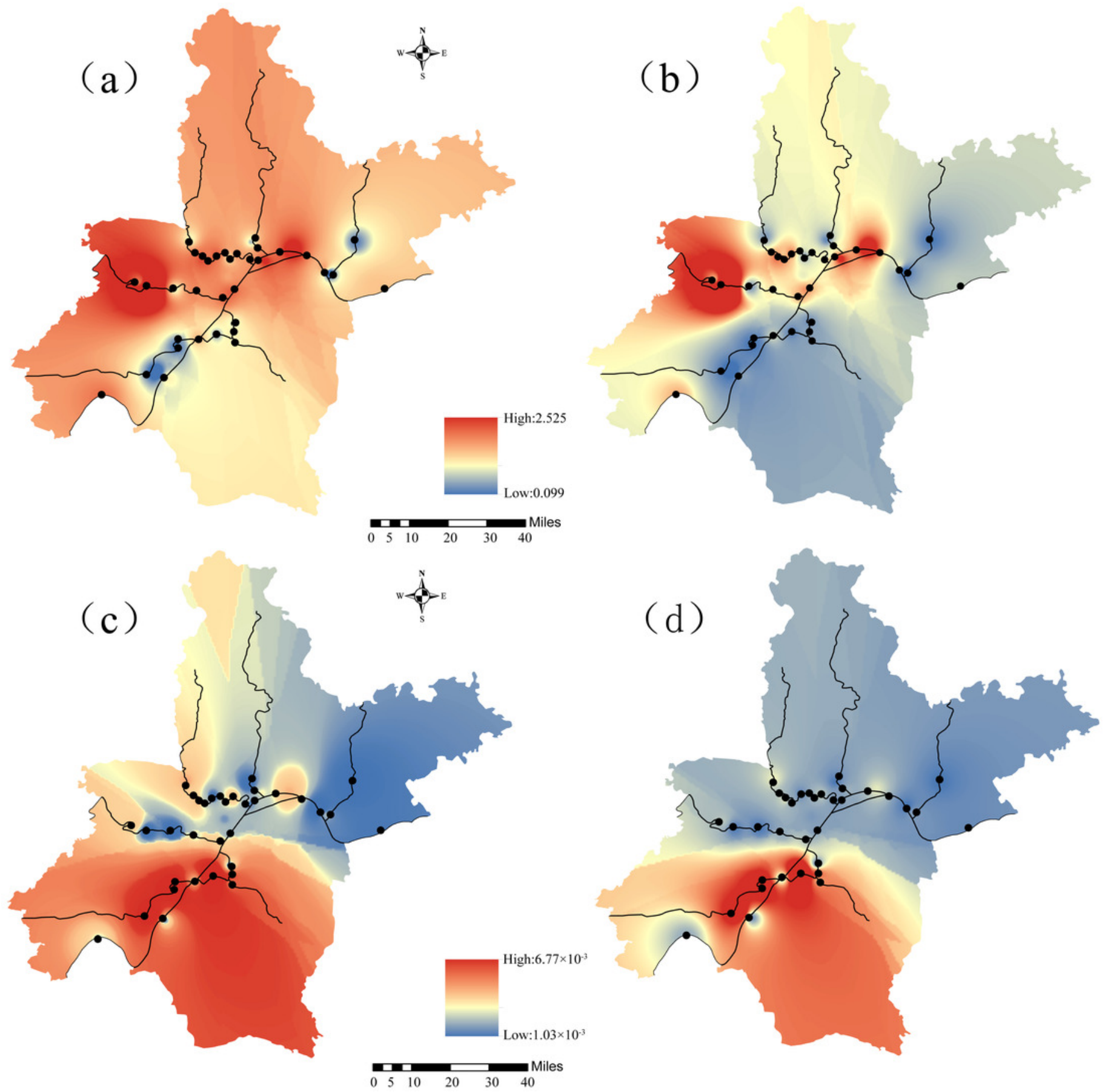




\section{Table $\mathbf{1}$ (on next page)}

Concentrations of dissolved heavy metals $(\mu \mathrm{g} / \mathrm{L}), \mathrm{pH}, \mathrm{EC}(\mu \mathrm{s} / \mathrm{cm})$ and $\mathrm{DO}(\mathrm{mg} / \mathrm{L})$ in rivers in Wuhan. 
1

\begin{tabular}{ccccccc}
\hline & Min & Max & Mean & Median & SD & K-S test $^{\mathbf{a}}$ \\
\hline $\mathbf{V}$ & 0.54 & 3.20 & 1.91 & 1.85 & 0.64 & 0.200 \\
$\mathbf{M n}$ & 0.00 & 7.66 & 0.90 & 0.16 & 1.88 & 0.000 \\
$\mathbf{F e}$ & 8.62 & 21.97 & 12.80 & 12.18 & 2.77 & 0.008 \\
$\mathbf{C o}$ & 0.03 & 0.19 & 0.06 & 0.05 & 0.04 & 0.000 \\
$\mathbf{N i}$ & 0.46 & 3.77 & 1.16 & 0.86 & 0.72 & 0.000 \\
$\mathbf{Z n}$ & 0.39 & 7.45 & 2.10 & 1.52 & 1.81 & 0.000 \\
$\mathbf{A s}$ & 2.51 & 11.15 & 3.72 & 3.13 & 1.74 & 0.000 \\
Mo & 1.07 & 6.00 & 2.28 & 1.73 & 1.26 & 0.000 \\
Sb & 1.14 & 16.29 & 4.29 & 4.07 & 2.73 & 0.100 \\
$\mathbf{p H}$ & 5.51 & 9.14 & 7.96 & 7.95 & 0.75 & 0.011 \\
$\mathbf{E C}$ & 213.00 & 661.00 & 344.00 & 329.03 & 92.71 & 0.013 \\
$\mathbf{D O}$ & 2.59 & 19.24 & 7.75 & 6.82 & 3.26 & 0.540 \\
\hline
\end{tabular}

${ }^{a}$ Kolmogorov-Smirnov test. 


\section{Table 2 (on next page)}

Comparison of heavy metal concentrations $(\mu \mathrm{g} / \mathrm{L})$ in rivers in Wuhan with water quality standards for drinking water and surface water. 


\begin{tabular}{|c|c|c|c|c|c|c|c|c|c|}
\hline & V & Mn & $\mathrm{Fe}$ & Co & $\mathbf{N i}$ & $\mathbf{Z n}$ & As & Mo & Sb \\
\hline Total & 1.91 & 0.90 & 12.80 & 0.06 & 1.16 & 2.10 & 3.72 & 2.28 & 4.29 \\
\hline Yangtze River & 1.83 & 0.29 & 11.66 & 0.03 & 0.81 & 1.93 & 3.05 & 1.44 & 5.15 \\
\hline Dongjin River & 1.21 & 0.21 & 13.67 & 0.06 & 0.72 & 0.97 & 6.54 & 1.75 & 1.55 \\
\hline Qingling River & 1.98 & 1.27 & 11.33 & 0.07 & 1.76 & 0.69 & 7.80 & 4.54 & 2.40 \\
\hline Xunsi River & 1.88 & 3.59 & 17.97 & 0.17 & 2.13 & 1.68 & 4.05 & 4.58 & 2.62 \\
\hline Han River & 2.93 & 1.78 & 14.70 & 0.04 & 0.89 & 4.32 & 3.02 & 3.62 & 6.84 \\
\hline Fu River & 1.95 & 0.96 & 13.06 & 0.07 & 1.52 & 2.00 & 3.27 & 2.00 & 4.51 \\
\hline Sheshui River & 1.28 & 0.04 & 10.51 & 0.06 & 0.83 & 1.33 & 2.89 & 1.26 & 3.41 \\
\hline Daoshui River & 1.07 & 0.09 & 9.35 & 0.06 & 1.22 & 2.14 & 2.80 & 1.28 & 1.58 \\
\hline World average & 0.71 & 34.00 & 66.00 & 0.15 & 0.80 & 0.60 & 0.62 & 0.42 & 0.07 \\
\hline China $^{b}$ & & 100 & 300 & 1000 & 20 & 1000 & 10 & 70 & 5 \\
\hline $\mathrm{WHO}^{\mathrm{c}}$ & & 500 & 300 & & 20 & 3000 & 10 & 70 & 5 \\
\hline $\mathrm{US}^{\mathrm{EPA}} \mathrm{d}^{\mathrm{d}}$ & & 500 & 300 & & & 5000 & 10 & & 6 \\
\hline I & & & & & & 50 & 50 & & \\
\hline II & & & & & & 1000 & 50 & & \\
\hline Grade $^{\mathrm{e}}$ & & & & & & 1000 & 50 & & \\
\hline IV & & & & & & 2000 & 100 & & \\
\hline V & & & & & & 2000 & 100 & & \\
\hline
\end{tabular}

${ }^{\text {a }}$ Gaillardet (2003)

${ }^{\mathrm{b}}$ Chinese drinking water standards (GB 5749-2006).

${ }^{c}$ WHO (2011) drinking water guidelines.

d US EPA (2003) drinking water standards.

${ }^{\mathrm{e}}$ Chinese surface water standards (GB 3838-2002). 


\section{Table 3(on next page)}

Varimax rotated component matrix for dissolved heavy metals (the significance of KMO and Bartlett's sphericity test is $<0.001$ ). 
1

\begin{tabular}{cccc}
\hline Eigenvalues & 3.74 & 2.11 & 1.19 \\
Variance (\%) & 35.25 & 25.81 & 17.21 \\
Cummulative (\%) & 35.25 & 61.07 & 78.27 \\
Variable & PC1 & PC2 & PC3 \\
\hline $\mathrm{V}$ & 0.02 & 0.80 & 0.45 \\
$\mathrm{Mn}$ & 0.76 & 0.30 & 0.14 \\
$\mathrm{Fe}$ & 0.75 & 0.28 & 0.33 \\
$\mathrm{Co}$ & 0.92 & -0.18 & 0.09 \\
$\mathrm{Ni}$ & 0.88 & -0.03 & -0.03 \\
$\mathrm{Zn}$ & 0.27 & 0.78 & -0.17 \\
$\mathrm{As}$ & 0.08 & -0.29 & 0.84 \\
$\mathrm{Mo}$ & 0.58 & 0.29 & 0.66 \\
$\mathrm{Sb}$ & -0.06 & 0.84 & -0.20 \\
\hline
\end{tabular}

Extraction method: Principal component analysis.

Rotation method: Varimax with Kaiser normalization. 


\section{Table 4 (on next page)}

Hazard quotient, Dermal permeability coefficient and Reference dose for heavy metals in rivers in Wuhan. 


\begin{tabular}{|c|c|c|c|c|c|c|c|c|c|}
\hline & \multicolumn{2}{|c|}{$\mathrm{HQ}_{\text {ingestion }}$} & \multicolumn{2}{|c|}{$\mathrm{HQ}_{\text {dermal }}$} & \multicolumn{2}{|c|}{$\mathrm{HI}$} & \multirow{2}{*}{$\begin{array}{l}\mathrm{K}_{\mathrm{p}}^{\mathrm{a}} \\
\mathrm{cm} / \mathrm{h}\end{array}$} & \multirow{2}{*}{$\begin{array}{c}\mathrm{RfD}_{\text {ingestion }}{ }^{\mathrm{bc}} \\
\mu \mathrm{g} / \mathrm{kg} / \text { day }\end{array}$} & \multirow{2}{*}{$\begin{array}{l}\mathrm{RfD}_{\text {dermal }}{ }^{\mathrm{bc}} \\
\mu \mathrm{g} / \mathrm{kg} / \text { day }\end{array}$} \\
\hline & Adults & Children & Adults & Children & Adults & Children & & & \\
\hline V & $5.22 \mathrm{E}-02$ & $7.80 \mathrm{E}-02$ & $5.45 \mathrm{E}-02$ & $1.61 \mathrm{E}-01$ & $1.07 \mathrm{E}-01$ & $2.39 \mathrm{E}-01$ & $2 \times 10^{-3}$ & 1 & 0.01 \\
\hline $\mathrm{Mn}$ & $1.03 \mathrm{E}-03$ & $1.54 \mathrm{E}-03$ & $1.35 \mathrm{E}-04$ & $3.98 \mathrm{E}-04$ & $1.17 \mathrm{E}-03$ & $1.94 \mathrm{E}-03$ & $1 \times 10^{-3}$ & 24 & 0.96 \\
\hline $\mathrm{Fe}$ & $5.01 \mathrm{E}-04$ & $7.48 \mathrm{E}-04$ & $1.31 \mathrm{E}-05$ & $3.86 \mathrm{E}-05$ & $5.14 \mathrm{E}-04$ & 7.87E-04 & $1 \times 10^{-3}$ & 700 & 140 \\
\hline $\mathrm{Co}$ & $5.66 \mathrm{E}-03$ & $8.46 \mathrm{E}-03$ & $5.91 \mathrm{E}-05$ & $1.74 \mathrm{E}-04$ & $5.72 \mathrm{E}-03$ & $8.63 \mathrm{E}-03$ & $4 \times 10^{-4}$ & 0.3 & 0.06 \\
\hline $\mathrm{Ni}$ & $1.59 \mathrm{E}-03$ & $2.37 \mathrm{E}-03$ & 4.15E-05 & $1.22 \mathrm{E}-04$ & $1.63 \mathrm{E}-03$ & $2.50 \mathrm{E}-03$ & $2 \times 10^{-4}$ & 20 & 0.8 \\
\hline $\mathrm{Zn}$ & $1.92 \mathrm{E}-04$ & $2.87 \mathrm{E}-04$ & $3.01 \mathrm{E}-06$ & $8.88 \mathrm{E}-06$ & $1.95 \mathrm{E}-04$ & $2.96 \mathrm{E}-04$ & $6 \times 10^{-4}$ & 300 & 60 \\
\hline As & $3.40 \mathrm{E}-01$ & $5.08 \mathrm{E}-01$ & $4.33 \mathrm{E}-03$ & $1.28 \mathrm{E}-02$ & $3.44 \mathrm{E}-01$ & $5.21 \mathrm{E}-01$ & $1 \times 10^{-3}$ & 0.3 & 0.123 \\
\hline Mo & $1.25 \mathrm{E}-02$ & $1.87 \mathrm{E}-02$ & $3.44 \mathrm{E}-04$ & $1.01 \mathrm{E}-03$ & $1.28 \mathrm{E}-02$ & $1.97 \mathrm{E}-02$ & $2 \times 10^{-3}$ & 5 & 1.9 \\
\hline $\mathrm{Sb}$ & $2.93 \mathrm{E}-01$ & $4.38 \mathrm{E}-01$ & $7.66 \mathrm{E}-02$ & $2.26 \mathrm{E}-01$ & $3.70 \mathrm{E}-01$ & $6.64 \mathrm{E}-01$ & $1 \times 10^{-3}$ & 0.4 & 0.008 \\
\hline
\end{tabular}

${ }^{a}$ US EPA (2004)

b Wang et al (2017)

${ }^{c}$ Wu et al (2009) 


\section{Table 5 (on next page)}

The $\mathrm{HI}$ values of $\mathrm{V}, \mathrm{Sb}$ and $\mathrm{As}$ and $\mathrm{CR}$ values of $\mathrm{As}$ in rivers in Wuhan. 


\begin{tabular}{ccccccccc}
\hline & \multicolumn{2}{c}{$\mathrm{V}(\mathrm{HI})$} & \multicolumn{2}{c}{$\mathrm{Sb}(\mathrm{HI})$} & \multicolumn{2}{c}{ As(HI) } & \multicolumn{2}{c}{ As(CR) } \\
\cline { 2 - 9 } & Adults & Children & Adults & Children & Adults & Children & Adults & Children \\
\hline Yangtze River & $9.95 \mathrm{E}-02$ & $2.23 \mathrm{E}-01$ & $4.65 \mathrm{E}-01$ & $8.34 \mathrm{E}-01$ & $2.78 \mathrm{E}-01$ & $4.21 \mathrm{E}-01$ & $1.24 \mathrm{E}-03$ & $1.85 \mathrm{E}-03$ \\
Dongjin River & $7.21 \mathrm{E}-02$ & $1.61 \mathrm{E}-01$ & $1.31 \mathrm{E}-01$ & $2.36 \mathrm{E}-01$ & $5.86 \mathrm{E}-01$ & $8.86 \mathrm{E}-01$ & $2.60 \mathrm{E}-03$ & $3.88 \mathrm{E}-03$ \\
Qingling River & $1.11 \mathrm{E}-01$ & $2.49 \mathrm{E}-01$ & $2.07 \mathrm{E}-01$ & $3.72 \mathrm{E}-01$ & $7.21 \mathrm{E}-01$ & $1.09 \mathrm{E}+00$ & $3.20 \mathrm{E}-03$ & $4.77 \mathrm{E}-03$ \\
Xunsi River & $1.05 \mathrm{E}-01$ & $2.35 \mathrm{E}-01$ & $2.27 \mathrm{E}-01$ & $4.07 \mathrm{E}-01$ & $3.75 \mathrm{E}-01$ & $5.67 \mathrm{E}-01$ & $1.66 \mathrm{E}-03$ & $2.48 \mathrm{E}-03$ \\
Han River & $1.72 \mathrm{E}-01$ & $3.85 \mathrm{E}-01$ & $4.50 \mathrm{E}-01$ & $8.08 \mathrm{E}-01$ & $2.91 \mathrm{E}-01$ & $4.40 \mathrm{E}-01$ & $1.29 \mathrm{E}-03$ & $1.93 \mathrm{E}-03$ \\
Fu River & $1.10 \mathrm{E}-01$ & $2.47 \mathrm{E}-01$ & $4.08 \mathrm{E}-01$ & $7.32 \mathrm{E}-01$ & $2.90 \mathrm{E}-01$ & $4.39 \mathrm{E}-01$ & $1.29 \mathrm{E}-03$ & $1.93 \mathrm{E}-03$ \\
Sheshui River & $7.18 \mathrm{E}-02$ & $1.61 \mathrm{E}-01$ & $2.94 \mathrm{E}-01$ & $5.28 \mathrm{E}-01$ & $2.67 \mathrm{E}-01$ & $4.04 \mathrm{E}-01$ & $1.19 \mathrm{E}-03$ & $1.77 \mathrm{E}-03$ \\
Daoshui River & $6.00 \mathrm{E}-02$ & $1.34 \mathrm{E}-01$ & $1.36 \mathrm{E}-01$ & $2.45 \mathrm{E}-01$ & $2.59 \mathrm{E}-01$ & $3.91 \mathrm{E}-01$ & $1.15 \mathrm{E}-03$ & $1.71 \mathrm{E}-03$ \\
\hline
\end{tabular}

